\title{
Capital structure, credit risk, and macroeconomic conditions ${ }^{\text {is }}$
}

\author{
Dirk Hackbarth ${ }^{\mathrm{a}}$, Jianjun Miao ${ }^{\mathrm{b}}$, Erwan Morellec ${ }^{\mathrm{c}, *}$ \\ ${ }^{a}$ Finance Department, Olin School of Business, Washington University in St. Louis, Campus Box 1133, \\ One Brookings Drive, St. Louis, MO 3130, USA \\ ${ }^{\mathrm{b}}$ Department of Economics, Boston University, 270 Bay State Road, Boston MA 02215, USA \\ ${ }^{\mathrm{c}}$ University of Lausanne, Swiss Finance Institute, and CEPR, Institute of Banking and Finance, Ecole des HEC, \\ University of Lausanne, Route de Chavannes 33, 1007 Lausanne, Switzerland
}

Received 21 December 2004; received in revised form 20 July 2005; accepted 13 October 2005 Available online 4 August 2006

\begin{abstract}
This paper develops a framework for analyzing the impact of macroeconomic conditions on credit risk and dynamic capital structure choice. We begin by observing that when cash flows depend on current economic conditions, there will be a benefit for firms to adapt their default and financing policies to the position of the economy in the business cycle phase. We then demonstrate that this simple observation has a wide range of empirical implications for corporations. Notably, we show that our model can replicate observed debt levels and the countercyclicality of leverage ratios. We also demonstrate that it can reproduce the observed term structure of credit spreads and generate strictly positive credit spreads for debt contracts with very short maturities. Finally, we characterize the impact of macroeconomic conditions on the pace and size of capital structure changes, and debt capacity.

(C) 2006 Elsevier B.V. All rights reserved.
\end{abstract}

JEL classification: G12; G32; G33

Keywords: Dynamic capital structure; Credit spreads; Macroeconomic conditions

\footnotetext{
${ }^{\text {¿2 }}$ We thank Pascal François, Bart Lambrecht, David T. Robinson, Pascal St Amour, Charles Trzcinka, Neng Wang, Lu Zhang, Alexei Zhdanov, an anonymous referee, and seminar participants at Indiana University, the University of Rochester, Washington University in St Louis, the Frank Batten Finance Conference at the College of William \& Mary for helpful comments. Erwan Morellec acknowledges financial support from FAME and from NCCR FINRISK of the Swiss National Science Foundation.

${ }^{*}$ Corresponding author. Tel.: + 4121 6923357; fax: 41216923435.

E-mail addresses: hackbarth@olin.wustl.edu (D. Hackbarth), miaoj@bu.edu (J. Miao), erwan.morellec@unil.ch (E. Morellec).
} 


\section{Introduction}

Since Modigliani and Miller (1958), economists have devoted much effort to understanding firms' financing policies. While most of the early literature analyzes financing decisions within qualitative models, recent research tries to provide quantitative guidance as well. ${ }^{1}$ However, despite the substantial development of this literature, little attention has been paid to the effects of macroeconomic conditions on credit risk and capital structure choices. This is relatively surprising since economic intuition suggests that the economy's business cycle phase should be an important determinant of default risk, and thus, of financing decisions. For example, we know that during recessions, consumers are likely to cut back on luxuries, and thus firms in the consumer durable goods sector should see their credit risk increase. Moreover, there is considerable evidence that macroeconomic conditions impact the probability of default (see Fama, 1986; Duffie and Singleton, 2003, pp. 45-47). Yet, existing models of firms' financing policies typically ignore this dimension.

In this paper we contend that macroeconomic conditions should have a large impact not only on credit risk but also on firms' financing decisions. Indeed, if one determines optimal leverage by balancing the tax benefit of debt and bankruptcy costs, then both the benefit and the cost of debt should depend on macroeconomic conditions. The tax benefit of debt obviously depends on the level of cash flows, which in turn should depend on whether the economy is in an expansion or in a contraction. In addition, expected bankruptcy costs depend on the probability of default and the loss given default, both of which should depend on the current state of the economy. As a result, variations in macroeconomic conditions should induce variations in optimal leverage.

The purpose of this paper is to provide a first step towards understanding the quantitative impact of macroeconomic conditions on credit risk and capital structure decisions. To do so, we develop a contingent claims model in which the firm's cash flows depend on both an idiosyncratic shock and an aggregate shock that reflects the state of the economy. The analysis is developed within a standard model of capital structure decisions in the spirit of Mello and Parsons (1992). Specifically, we consider a firm that has exclusive access to a project that yields a stochastic stream of cash flows. The firm is levered because debt allows it to shield part of its income from taxation. However, leverage is limited because debt financing increases the likelihood of costly financial distress. Once debt has been issued, shareholders have the option to default on their obligations. Based on this endogenous modeling of default, the paper derives valuation formulas for coupon-bearing

\footnotetext{
${ }^{1}$ Since the seminal papers by Merton (1974), Black and Cox (1976) and Brennan and Scwhartz (1978), the literature on the valuation of corporate securities and financing decisions has substantially developed. Mello and Parsons (1992) and Leland (1994) endogenize shareholders' default decision and determine optimal capital structure. Fischer et al. (1989), Leland (1998), and Goldstein et al. (2001) model dynamic financing decisions. Fan and Sundaresan (2000), David (2001), François and Morellec (2004), and Hege and Mella-Barral (2005) analyze the effects of strategic default. Morellec (2001) analyzes the impact of asset liquidity on leverage and the structure of debt contracts. Fries et al. (1997), Lambrecht (2001), and Miao (2005) investigate the interaction between capital structure and product market competition. Cadenillas et al. (2004), and Morellec (2004) examine the role of manager-stockholder conflicts in explaining debt levels. Duffie and Lando (2001) incorporate imperfect information and learning. Hackbarth (2004), Hennessy (2004), and Childs et al. (2005) investigate the impact of financing policy on investment policy. Bhanot and Mello (2006) examine rating triggers.
} 
debt with arbitrary maturity, equity, and levered firm value. We then use these closed-form expressions to analyze credit risk and determine optimal leverage.

The analysis shows that, when the value of the aggregate shock shifts between different states (boom or recession), the shareholders' default policy is characterized by a different default threshold for each state. Under this policy the state space can be partitioned into various domains including a continuation region in which no default occurs. Outside of this region, default can occur either because cash flows reach the default threshold in a given state or because of a change in the state of the aggregate shock. In other words, aggregate shocks generate some time-series variation in the present value of future cash flows to current cash flows that may induce the firm to default following a change in macroeconomic conditions. The paper also demonstrates that while variations in idiosyncratic shocks are unlikely to explain the clustering of exit decisions observed in many markets, changes in macroeconomic conditions provide the basis for such phenomena.

Following the analysis of the shareholders' default policy, we examine the implications of the model for financing decisions. The leverage ratios that the model generates are in line with those observed in practice. In addition, the model predicts that leverage is countercyclical, consistent with the evidence reported by Korajczyk and Levy (2003). We also examine dynamic capital structure choice and relate both the pace and the size of capital structure changes to macroeconomic conditions. ${ }^{2}$ In particular, we find that firms should adjust their capital structure more often and by smaller amounts in booms than in recessions. Another quantity of interest for corporations is the credit spread on corporate debt. We show that the model can generate a term structure of credit spreads that is in line with empirically observed credit spreads on corporate debt and strictly positive credit spreads for short term debt issues.

The remainder of the paper is organized as follows. Section 2 develops a static model of capital structure decisions in which firms' cash flows depend on macroeconomic conditions. Section 3 determines the prices of corporate securities. Section 4 discusses implications. Section 5 examines dynamic capital structure choice. Section 6 concludes.

\section{The model}

\subsection{Assumptions}

We construct a partial equilibrium model of firms' financing decisions. Throughout the paper, agents are risk neutral and discount cash flows at a constant interest rate $r{ }^{3}$ Time is

\footnotetext{
${ }^{2}$ The study by Drobetz and Wanzenried (2004) provides early empirical support for this hypothesis.

${ }^{3}$ Throughout the analysis, the risk free rate $r$ is constant and, as a result, does not move with macroeconomic conditions. This is supported by the weak historical correlation (presumably due to adjustments in monetary policy) between fluctuations in real GDP or fluctuations in real consumption and the rate of return on risk-free debt. More specifically, over the period 1959:3 to 1998:4, the correlation between the quarterly growth rate on real consumption per capita (source: NIPA on non durables and services) and the three-month T-bill rate on the secondary market is -0.0031 . Over that same period, the correlation between the quarterly growth rate on GDP and the three-month T-bill rate on the secondary market is 0.0561. In addition, Campbell (1999) reports that the "the annualized standard deviation of the ex post real returns on U.S. Treasury bills is $1.8 \%$ and much of this is due to short-term inflation risk. [...] Thus, the standard deviation of the ex ante real interest rate is considerably smaller."
} 
continuous and uncertainty is modeled by a complete probability space $(\Omega, \mathscr{F}, \mathscr{P})$. We consider an infinitely-lived firm with assets that generate a continuous stream of cash flows. Management acts in the best interests of shareholders. Corporate taxes are paid at a rate $\tau$ on operating cash flows, and full offsets of corporate losses are allowed. At any time $t$, the firm's instantaneous operating profit (EBIT) satisfies:

$$
f\left(x_{t}, y_{t}\right)=x_{t} y_{t},
$$

where $\left(y_{t}\right)_{t \geqslant 0}$ is an aggregate shock that reflects the state of the economy, and $\left(x_{t}\right)_{t \geqslant 0}$ is an idiosyncratic shock that reflects the firm-level productivity uncertainty. ${ }^{4}$ We presume that $\left(x_{t}\right)_{t \geqslant 0}$ is independent of $\left(y_{t}\right)_{t \geqslant 0}$ and evolves according to the geometric Brownian motion:

$$
\mathrm{d} x_{t}=\mu x_{t} \mathrm{~d} t+\sigma x_{t} \mathrm{~d} W_{t}, \quad x_{0}>0 \text { given, }
$$

where $\mu<r$ and $\sigma>0$ are constant parameters and $\left(W_{t}\right)_{t \geqslant 0}$ is a standard Brownian motion defined on $(\Omega, \mathscr{F}, \mathscr{P})$. Both $x$ and $y$ are observable to all agents.

Because the firm pays taxes on corporate income, it has an incentive to issue debt. Following Leland (1998), we consider finite-maturity debt structures in a stationary environment. The firm has debt with constant principal $p$ and paying a constant total coupon $c$ at each moment in time. It instantaneously rolls over a fraction $m$ of its total debt. That is, the firm continuously retires outstanding debt principal at a rate $m p$ (except when bankruptcy occurs), and replaces it with new debt vintages of identical coupon, principal, and seniority. Therefore, any finite-maturity debt policy is completely characterized by the tuple $(c, m, p)$. In the absence of bankruptcy, the average debt maturity $\bar{T}$ equals $1 / m$.

Economically, our finite-maturity debt assumption corresponds to commonly used sinking fund provisions (e.g., Smith and Warner, 1979). Mathematically, this modeling approach is equivalent to debt amortization being simply an exponential function of time. Since the total coupon rate and the sinking fund requirement are fixed, we obtain a timehomogeneous setting akin to Leland (1998), Duffie and Lando (2001), and Morellec (2001). We further assume that the debt coupon is initially determined such that debt value equals principal value. That is, debt is issued at par. ${ }^{5}$ Proceeds from the debt issue are paid out as a cash distribution to shareholders at the time of flotation.

Once debt has been issued, shareholders' only decision is to select the default policy that maximizes equity value. We presume that if the firm defaults on its debt obligations, it is immediately liquidated. In the event of default, the liquidation value of the firm is $\alpha A\left(x_{t}\right)$, where $\alpha \in(0,1)$ is a regime-dependent recovery rate on assets and $A\left(x_{t}\right)$ is the value of unlevered assets. Section 5 extends the basic model to incorporate dynamic capital structure choice. In this more general setting, shareholders have to decide on the initial amount of debt to issue as well as the optimal default and restructuring policies.

\footnotetext{
${ }^{4}$ Suppose that the firm's production function is $Y_{t}=A_{t} N_{t}^{\gamma}$, where $Y_{t}$ is output, $A_{t}$ is the firm-level productivity shock, $N_{t}$ is labor, and $\gamma \in(0,1)$ represents returns to scale. Let the inverse demand function be given by $p_{t}=h_{t} Y_{t}^{-1 / \varepsilon}$, where $h_{t}$ represents the aggregate demand shock and $\varepsilon>0$ is the elasticity of demand. Then the firm's profit is given by $f_{t}=\max _{N_{t}} p_{t} Y_{t}-w_{t} N_{t}$, where $w_{t}$ is the wage rate, which is assumed to be constant. Solving yields $f_{t}=\theta^{\theta /(1-\theta)}[1-\theta] h_{t}^{1 /(1-\theta)} A_{t}^{1 / \gamma} w_{t}^{-\theta /(1-\theta)}$ with $\theta=\gamma(\varepsilon-1) / \varepsilon$. Letting $y_{t}=\theta^{\theta /(1-\theta)}[1-\theta] h_{t}^{1 /(1-\theta)}$ and $x_{t}=A_{t}^{1 / \gamma} w_{t}^{-\theta /(1-\theta)}$, we obtain $f_{t}=x_{t} y_{t}$ as in Eq. (1).

${ }^{5}$ This assumption implies that the tax benefits of debt only hinge upon the chosen debt coupon and hence do not depend on whether debt is initially floated at a discount or premium to principal value.
} 


\subsection{Relation with existing literature}

Before proceeding to the analysis, it might be helpful to briefly contrast the present model with some related lines of research.

Contingent claims analysis. As in previous contingent claims models, we analyze equity in a levered firm as an option on the firm's assets and model the decision to default as a stopping problem. The distinguishing feature of our model is that the current cash flow depends on current macroeconomic conditions (expansion or contraction). Because the decision to default balances the present value of cash flows in continuation with the present value of cash flows in default, this implies that the decision to default also depends on current macroeconomic conditions. This feature is unique to our model and cannot be reproduced by introducing discontinuities through a jump-diffusion model.

Regime shifts and firms' policy choices. Recent work by Guo et al. (GMM, 2005) investigates the impact of discrete changes in the growth rate and volatility of cash flows on firms' investment decisions. One important point of departure from GMM is that we introduce regime shifts in the aggregate shock only and the aggregate shock influences cash flows multiplicatively. Another important difference is that GMM analyze real investment whereas we examine capital structure decisions. Finally, from a technical point of view, GMM solve a control problem in which control policies change the underlying diffusion process whereas we solve a stopping problem.

\section{Valuation of corporate securities}

In this section, we derive the values of corporate debt and equity as well as the default thresholds selected by shareholders. These results will be used below to analyze credit risk and capital structure decisions. To examine the impact of macroeconomic conditions on these quantities in the simplest possible environment, we assume that the aggregate shock $\left(y_{t}\right)_{t \geqslant 0}$ can only take two values: $y_{L}$ and $y_{H}$ with $y_{H}>y_{L}>0$. In addition, we presume that $y_{t}$ is observable and that its transition probability follows a Poisson law, such that $\left(y_{t}\right)_{t \geqslant 0}$ is a two-state Markov chain. Let $\lambda_{i}>0$ denote the rate of leaving state $i$ and $\ell_{i}$ denote the time to leave state $i$. Within the present model, the exponential law holds:

$$
P\left(\ell_{i}>t\right)=\mathrm{e}^{-\lambda_{i} t}, \quad i=H, L,
$$

and there is a probability $\lambda_{i} \Delta t$ that the value of the shock $\left(y_{t}\right)_{t \geqslant 0}$ changes from $y_{i}$ to $y_{j}$ during an infinitesimal time interval $\Delta t$. In addition, the expected duration of regime $L$ is $\left(\lambda_{L}\right)^{-1}$ and the average fraction of time spent in that regime is $\lambda_{H}\left(\lambda_{L}+\lambda_{H}\right)^{-1}$.

\subsection{Finite-maturity debt value}

We start by determining the value of corporate debt. Debt value equals the sum of the present value of the cash flows that accrue to debtholders until the default time and the change in this present value that arises in default. Since the latter component depends on the firm's abandonment value, we start by deriving this value.

\subsubsection{Abandonment value}

We follow Mello and Parsons (1992) and Leland (1994) by presuming that the abandonment value of the firm equals the value of unlevered assets, i.e., the unlimited 
liability value of a perpetual claim to the current flow of after-tax operating income. Denoting by $E_{\mathscr{P}}[\cdot \mid \cdot]$ the conditional expectation operator associated with $\mathscr{P}$, we can thus write this value as

$$
A_{i}(x)=E_{\mathscr{P}}\left[\int_{0}^{\infty} \mathrm{e}^{-r t}(1-\tau) x_{t} y_{t} \mathrm{~d} t \mid x_{0}=x, y_{0}=y_{i}\right], \quad i=L, H .
$$

Since the level of the firm's operating cash flows depend on the current regime, so does the firm's abandonment value. Applying Itô's lemma and simplifying, we find that $A_{i}(x)$ satisfies the system of ordinary differential equations (ODEs):

$$
\begin{aligned}
& r A_{L}(x)=\mu x A_{L}^{\prime}(x)+\frac{\sigma^{2}}{2} x^{2} A_{L}^{\prime \prime}(x)+\lambda_{L}\left[A_{H}(x)-A_{L}(x)\right]+(1-\tau) x y_{L}, \\
& r A_{H}(x)=\mu x A_{H}^{\prime}(x)+\frac{\sigma^{2}}{2} x^{2} A_{H}^{\prime \prime}(x)+\lambda_{H}\left[A_{L}(x)-A_{H}(x)\right]+(1-\tau) x y_{H} .
\end{aligned}
$$

Within the current framework, the expected rate of return on corporate securities is $r$. Thus, the left-hand side of these equations reflects the required rate of return for holding the asset per unit of time. The right-hand side is the expected change in the asset value (i.e., the realized rate of return). These expressions are similar to those derived in standard contingent claims models. However, they contain the additional term $\lambda_{i}\left[A_{j}(x)-A_{i}(x)\right]$, which reflects the impact of the aggregate shock on the value functions. This term is the product of the instantaneous probability of a regime shift and the change in the value function occurring after a regime shift.

Solving these ODEs subject to the boundedness conditions

$$
\lim _{x \rightarrow \infty} \frac{A_{i}(x)}{x}<\infty \text { and } \lim _{x \rightarrow 0} A_{i}(x)<\infty
$$

yields the following expression for the firm's abandonment value:

$$
A_{i}(x)=(1-\tau) K_{i} x, \quad i=L, H,
$$

where

$$
\begin{aligned}
K_{H} & =\frac{y_{H}}{r-\mu}-\frac{\lambda_{H}\left(y_{H}-y_{L}\right)}{(r-\mu)\left(r-\mu+\lambda_{L}+\lambda_{H}\right)}, \\
K_{L} & =\frac{y_{L}}{r-\mu}+\frac{\lambda_{L}\left(y_{H}-y_{L}\right)}{(r-\mu)\left(r-\mu+\lambda_{L}+\lambda_{H}\right)} .
\end{aligned}
$$

In the above two expressions, the first term on the right hand side is the abandonment value of the firm in the absence of regime shifts. The second term adjusts this abandonment value to reflect the possibility of a regime shift (thereby attenuating implied changes).

\subsubsection{Debt value}

Consider next the value of corporate debt. Denote by $d_{i}^{0}(x, c, m, p, t)$ the date $t$ value of debt issued at time 0 . These original debtholders receive a total payment rate of $\mathrm{e}^{-m t}(c+m p)$ as long as the firm is solvent. Now define the value of total outstanding debt at any date $t$ by $d_{i}(x, c, m, p)=\mathrm{e}^{m t} \mathrm{~d}_{i}^{0}(x, c, m, p, t)$. Because $d_{i}(x, c, m, p)$ receives a constant payment rate $c+m p$, it is independent of $t$.

Let $x_{i}^{*}$ denote the default threshold that maximizes equity value in regime $i=H, L$. Since $f$ is strictly increasing in $y$ and $y_{L}<y_{H}$, it is straightforward to show that $x_{L}^{*}>x_{H}^{*}$. 
That is, the firm defaults earlier in recessions than in expansions. Using Itô's lemma, it can be shown that the total value of outstanding debt solves the following system of ODEs (the arguments for the debt structure $c, m$, and $p$ are omitted):

- In the region $x_{H}^{*} \leqslant x \leqslant x_{L}^{*}$,

$$
(r+m) d_{H}(x)=\mu x d_{H}^{\prime}(x)+\frac{\sigma^{2}}{2} x^{2} d_{H}^{\prime \prime}(x)+\lambda_{H}\left[\alpha_{L} A_{L}(x)-d_{H}(x)\right]+c+m p .
$$

- In the region $x \geqslant x_{L}^{*}$,

$$
\begin{aligned}
& (r+m) d_{L}(x)=\mu x d_{L}^{\prime}(x)+\frac{\sigma^{2}}{2} x^{2} d_{L}^{\prime \prime}(x)+\lambda_{L}\left[d_{H}(x)-d_{L}(x)\right]+c+m p, \\
& (r+m) d_{H}(x)=\mu x d_{H}^{\prime}(x)+\frac{\sigma^{2}}{2} x^{2} d_{H}^{\prime \prime}(x)+\lambda_{H}\left[d_{L}(x)-d_{H}(x)\right]+c+m p .
\end{aligned}
$$

As is the case for the abandonment value, these equations are similar to those obtained in the standard diffusion case (e.g., Leland, 1998), and they incorporate an additional term that reflects the impact of the possibility of a change in the value of the aggregate shock on asset prices. This term equals $\lambda_{H}\left[\alpha_{L} A_{L}(x)-d_{H}(x)\right]$ in Eq. (11), where $\alpha_{L}$ is the recovery rate in a recession, since it will be optimal for shareholders to default subsequent to a change of $y_{t}$ from $y_{H}$ to $y_{L}$ on the interval $\left[x_{H}^{*}, x_{L}^{*}\right]$. (See Section 3.3.2 for a discussion.)

This system of ODEs is associated with the following four boundary conditions:

$$
\begin{aligned}
d_{L}\left(x_{L}^{*}, c, m, p\right) & =\alpha_{L} A_{L}\left(x_{L}^{*}\right), \\
d_{H}\left(x_{H}^{*}, c, m, p\right) & =\alpha_{H} A_{H}\left(x_{H}^{*}\right), \\
\lim _{x \downarrow x_{L}^{*}} d_{H}(x, c, m, p) & =\lim _{x \uparrow x_{L}^{*}} d_{H}(x, c, m, p), \\
\lim _{x \downarrow x_{L}^{*}} d_{H}^{\prime}(x, c, m, p) & =\lim _{x \uparrow x_{L}^{*}} d_{H}^{\prime}(x, c, m, p),
\end{aligned}
$$

where derivatives are taken with respect to $x$. The value-matching (14)-(15) impose an equality between the value of corporate debt and the value of cash flows accruing to debtholders in default. Because the decision to default does not belong to bondholders, these value-matching conditions are not associated with additional optimality conditions. In addition, because cash flows to claimholders are given by a (piecewise) continuous Borel-bounded function, the debt value functions $d_{i}(\cdot)$ are piecewise $\mathscr{C}^{2}$ (see Theorem 4.9, pp. 271 in Karatzas and Shreve, 1991). Therefore, the value function $d_{H}(\cdot)$ is $\mathscr{C}^{0}$ and $\mathscr{C}^{1}$ and satisfies the continuity and smoothness (16)-(17). Solving Eqs. (12)-(17), we obtain the following proposition, where, for notational convenience, we identify finite-maturity debt parameters by bars (e.g., $\bar{\xi}$ or $\bar{T}$ ).

Proposition 1. When the firm's operating cash flows are given by Eq. (1) and it has issued finite-maturity debt with coupon payment $c$, instantaneous debt retirement rate $m$, and total principal $p$, the value of corporate debt in regime $i=L, H$ is given by

$$
d_{L}(x, c, m, p)= \begin{cases}\bar{A} x^{\bar{\xi}}-\lambda_{L} \bar{B} x^{\bar{\gamma}}+\frac{c+m p}{r+m}, & x \geqslant x_{L}^{*}, \\ \alpha_{L}(1-\tau) K_{L} x, & x \leqslant x_{L}^{*},\end{cases}
$$


and

$$
d_{H}(x, c, m, p)= \begin{cases}\bar{A} x^{\bar{\xi}}+\lambda_{H} \bar{B} x^{\bar{\gamma}}+\frac{c+m p}{r+m}, & x \geqslant x_{L}^{*}, \\ \bar{C} x^{\bar{\beta}_{1}}+\bar{D} x^{\bar{\beta}_{2}}+\lambda_{H} \frac{(1-\tau) \alpha_{L} K_{L} x}{r-\mu+m+\lambda_{H}}+\frac{c+m p}{r+\lambda_{H}+m}, & x_{H}^{*} \leqslant x \leqslant x_{L}^{*}, \\ \alpha_{H}(1-\tau) K_{H} x, & x \leqslant x_{H}^{*},\end{cases}
$$

where the endogenous default thresholds $x_{L}^{*}$ and $x_{H}^{*}$ are reported in Proposition 4, the parameters $K_{L}$ and $K_{H}$ are given in Eqs. (9)-(10), the exponents $\bar{\gamma}, \bar{\xi}, \bar{\beta}_{1}$, and $\bar{\beta}_{2}$ are defined by

$$
\begin{aligned}
\bar{\xi} & =0.5-\mu / \sigma^{2}-\sqrt{\left(0.5-\mu / \sigma^{2}\right)^{2}+2(r+m) / \sigma^{2}}, \\
\bar{\gamma} & =0.5-\mu / \sigma^{2}-\sqrt{\left(0.5-\mu / \sigma^{2}\right)^{2}+2\left(r+m+\lambda_{L}+\lambda_{H}\right) / \sigma^{2}}, \\
\bar{\beta}_{1} & =0.5-\mu / \sigma^{2}+\sqrt{\left(0.5-\mu / \sigma^{2}\right)^{2}+2\left(r+m+\lambda_{H}\right) / \sigma^{2}}, \\
\bar{\beta}_{2} & =0.5-\mu / \sigma^{2}-\sqrt{\left(0.5-\mu / \sigma^{2}\right)^{2}+2\left(r+m+\lambda_{H}\right) / \sigma^{2}},
\end{aligned}
$$

the constants $\bar{A}, \bar{B}, \bar{C}$, and $\bar{D}$ satisfy

$$
\begin{aligned}
\bar{A} & =\frac{\bar{w}_{1}+\lambda_{L} \bar{B}\left(x_{L}^{*}\right)^{\bar{\gamma}}}{\left(x_{L}^{*}\right)^{\bar{\xi}}}, \\
\bar{B} & =\frac{\left[\bar{w}_{4}+\bar{\xi} \bar{w}_{1}-\bar{\beta}_{1} \bar{w}_{2}\left(x_{L}^{*} / x_{H}^{*}\right)^{\bar{\beta}_{1}}\right] \bar{w}_{6}-\left[\bar{w}_{3}+\bar{w}_{1}-\bar{w}_{2}\left(x_{L}^{*} / x_{H}^{*}\right)^{\bar{\beta}_{1}}\right] \bar{w}_{8}}{\bar{w}_{5} \bar{w}_{8}-\bar{w}_{6} \bar{w}_{7}}, \\
\bar{C} & =\frac{\bar{w}_{2}-\bar{D}\left(x_{H}^{*}\right)^{\bar{\beta}_{2}}}{\left(x_{H}^{*}\right)^{\bar{\beta}_{1}}}, \\
\bar{D} & =\frac{\left[\bar{w}_{4}+\bar{\xi} \bar{w}_{1}-\bar{\beta}_{1} \bar{w}_{2}\left(x_{L}^{*} / x_{H}^{*}\right)^{\bar{\beta}_{1}}\right] \bar{w}_{5}-\left[\bar{w}_{3}+\bar{w}_{1}-\bar{w}_{2}\left(x_{L}^{*} / x_{H}^{*}\right)^{\bar{\beta}_{1}}\right] \bar{w}_{7}}{\bar{w}_{5} \bar{w}_{8}-\bar{w}_{6} \bar{w}_{7}},
\end{aligned}
$$

and

$$
\begin{array}{ll}
\bar{w}_{1}=(1-\tau) \alpha_{L} K_{L} x_{L}^{*}-\frac{c+m p}{r+m}, & \bar{w}_{2}=\left[(1-\tau) \alpha_{H} K_{H}+\frac{\bar{w}_{4}}{x_{L}^{*}}\right] x_{H}^{*}-\frac{c+m p}{r+\lambda_{H}+m}, \\
\bar{w}_{3}=\bar{w}_{4}+\frac{c+m p}{r+m}-\frac{c+m p}{r+\lambda_{H}+m}, & \bar{w}_{4}=-\lambda_{H} \frac{(1-\tau) \alpha_{L} K_{L} x_{L}^{*}}{r-\mu+m+\lambda_{H}}, \\
\bar{w}_{5}=\left(\lambda_{L}+\lambda_{H}\right)\left(x_{L}^{*}\right)^{\bar{\gamma}}, & \bar{w}_{6}=\left(x_{L}^{*}\right)^{\bar{\beta}_{2}}-\left(x_{H}^{*}\right)^{\bar{\beta}_{2}}\left(\frac{x_{L}^{*}}{x_{H}^{*}}\right)^{\bar{\beta}_{1}}, \\
\bar{w}_{7}=\left(\bar{\xi} \lambda_{L}+\bar{\gamma} \lambda_{H}\right)\left(x_{L}^{*}\right)^{\bar{\gamma}}, & \bar{w}_{8}=\bar{\beta}_{2}\left(x_{L}^{*}\right)^{\bar{\beta}_{2}}-\bar{\beta}_{1}\left(x_{H}^{*}\right)^{\bar{\beta}_{2}}\left(\frac{x_{L}^{*}}{x_{H}^{*}}\right)^{\bar{\beta}_{1}} .
\end{array}
$$

Proposition 1 provides the value of corporate debt when cash flows from assets in place depend on the realizations of both an idiosyncratic shock and an aggregate shock. The 
value of corporate debt is equal to the sum of the value of a perpetual entitlement to the current debt service flow and the change in value that occurs either after a sudden change in the value of the aggregate shock or when the idiosyncratic shock smoothly reaches a default boundary $x_{i}^{*}$. In these valuation formulas, the default threshold is determined by shareholders and hence is an exogenous parameter for bondholders.

Proposition 1 shows that the value of corporate debt in the continuation region $\left[x_{L}^{*}, \infty\right)$ has three components. First, it incorporates the value of a perpetual claim to the stream of risk-free coupon and debt retirement payments. Second, it reflects the change in value arising when the idiosyncratic shock reaches the default boundary $x_{L}^{*}$ from above for the first time; i.e., debtholders' recoveries. Third, it captures the change in default risk that occurs following a change in the value of the aggregate shock. The value of corporate debt in the transient region $\left[x_{H}^{*}, x_{L}^{*}\right]$ also has three components. First, it includes the value of a perpetual claim to the stream of non defaultable debt payments, $(c+m p) /\left(r+\lambda_{H}+m\right)$. Because the rate of leaving state $i=H$ is $\lambda_{H}$, the discount rate is increased by $\lambda_{H}$ to reflect the possibility of a change in the value of the aggregate shock. Second, it reflects the change in debt value that arises when the value of the idiosyncratic shock either reaches the default boundary $x_{H}^{*}$ the first time from above or the upper boundary of that region $x_{L}^{*}$ from below. Third, it captures the change in value that arises when default occurs suddenly (i.e., following a change of $y_{t}$ from $y_{H}$ to $y_{L}$ on the interval $\left[x_{H}^{*}, x_{L}^{*}\right]$ ).

\subsection{Firm value}

We now turn to the value of the levered firm. Total firm value equals the sum of the unlimited liability value of a perpetual claim to the current flow of after-tax operating income, plus the present value of a perpetual claim to the current flow of tax benefits of debt, minus the change in those present values arising in default. Thus, the levered firm value $v_{i}(x)$ satisfies the following system of ODEs (the argument for the coupon $c$ is omitted):

- In the region $x \geqslant x_{L}^{*}$,

$$
\begin{aligned}
& r v_{L}(x)=\mu x v_{L}^{\prime}(x)+\frac{\sigma^{2}}{2} x^{2} v_{L}^{\prime \prime}(x)+\lambda_{L}\left[v_{H}(x)-v_{L}(x)\right]+(1-\tau) x y_{L}+\tau c, \\
& r v_{H}(x)=\mu x v_{H}^{\prime}(x)+\frac{\sigma^{2}}{2} x^{2} v_{H}^{\prime \prime}(x)+\lambda_{H}\left[v_{L}(x)-v_{H}(x)\right]+(1-\tau) x y_{H}+\tau c .
\end{aligned}
$$

- In the region $x_{H}^{*} \leqslant x \leqslant x_{L}^{*}$,

$$
r v_{H}(x)=\mu x v_{H}^{\prime}(x)+\frac{\sigma^{2}}{2} x^{2} v_{H}^{\prime \prime}(x)+\lambda_{H}\left[\alpha_{L} A_{L}(x)-v_{H}(x)\right]+(1-\tau) x y_{H}+\tau c .
$$

This system of ODEs is associated with the following four boundary conditions:

$$
\begin{aligned}
& v_{L}\left(x_{L}^{*}, c\right)=\alpha_{L} A_{L}\left(x_{L}^{*}\right), \\
& v_{H}\left(x_{H}^{*}, c\right)=\alpha_{H} A_{H}\left(x_{H}^{*}\right), \\
& \lim _{x \downarrow x_{L}^{*}} v_{H}(x, c)=\lim _{x \uparrow x_{L}^{*}} v_{H}(x, c), \\
& \lim _{x \downarrow x_{L}^{*}} v_{H}^{\prime}(x, c)=\lim _{x \uparrow x_{L}^{*}} v_{H}^{\prime}(x, c) .
\end{aligned}
$$


The value-matching conditions (29)-(30) impose an equality between levered firm value and abandonment value at the time of default. Again, Eqs. (31)-(32) are continuity and smoothness conditions. Using Eqs. (26)-(32), we obtain the next result.

Proposition 2. When the firm's operating cash flows are given by Eq. (1), the value of the levered firm in regime $i=L, H$ is given by

$$
v_{L}(x, c)= \begin{cases}A x^{\xi}-\lambda_{L} B x^{\gamma}+(1-\tau) K_{L} x+\frac{\tau c}{r}, & x \geqslant x_{L}^{*} \\ \alpha_{L}(1-\tau) K_{L} x, & x \leqslant x_{L}^{*}\end{cases}
$$

and

$$
v_{H}(x, c)= \begin{cases}A x^{\xi}+\lambda_{H} B x^{\gamma}+(1-\tau) K_{H} x+\frac{\tau c}{r}, & x \geqslant x_{L}^{*}, \\ C x^{\beta_{1}}+D x^{\beta_{2}}+\lambda_{H} \frac{(1-\tau) \alpha_{L} K_{L} x}{r-\mu+\lambda_{H}}+\frac{(1-\tau) y_{H} x}{r-\mu+\lambda_{H}}+\frac{\tau c}{r+\lambda_{H}}, & x_{H}^{*} \leqslant x \leqslant x_{L}^{*}, \\ \alpha_{H}(1-\tau) K_{H} x, & x \leqslant x_{H}^{*},\end{cases}
$$

where the endogenous default thresholds $x_{L}^{*}$ and $x_{H}^{*}$ are reported in Proposition 4 , the parameters $K_{L}$ and $K_{H}$ are given in Eqs. (9)-(10), the exponents $\gamma, \xi, \beta_{1}$, and $\beta_{2}$ are defined as in Eqs. (20)-(23) with $m=0$, and the constants $A, B, C$, and D satisfy

$$
\begin{aligned}
& A=\frac{w_{1}+\lambda_{L} B\left(x_{L}^{*}\right)^{\gamma}}{\left(x_{L}^{*}\right)^{\xi}}, \\
& B=\frac{\left[w_{4}+\xi w_{1}-\beta_{1} w_{2}\left(x_{L}^{*} / x_{H}^{*}\right)^{\beta_{1}}\right] w_{6}-\left[w_{3}+w_{1}-w_{2}\left(x_{L}^{*} / x_{H}^{*}\right)^{\beta_{1}}\right] w_{8}}{w_{5} w_{8}-w_{6} w_{7}} \\
& C=\frac{w_{2}-D\left(x_{H}^{*}\right)^{\beta_{2}}}{\left(x_{H}^{*}\right)^{\beta_{1}}}, \\
& D=\frac{\left[w_{4}+\xi w_{1}-\beta_{1} w_{2}\left(x_{L}^{*} / x_{H}^{*}\right)^{\beta_{1}}\right] w_{5}-\left[w_{3}+w_{1}-w_{2}\left(x_{L}^{*} / x_{H}^{*}\right)^{\beta_{1}}\right] w_{7}}{w_{5} w_{8}-w_{6} w_{7}}
\end{aligned}
$$

where

$$
\begin{gathered}
w_{1}=(1-\tau)\left(\alpha_{L}-1\right) K_{L} x_{L}^{*}-\frac{\tau c}{r}, \quad w_{2}=(1-\tau)\left(\alpha_{H} K_{H}-\frac{y_{H}+\lambda_{H} \alpha_{L} K_{L}}{r-\mu+\lambda_{H}}\right) x_{H}^{*}-\frac{\tau c}{r+\lambda_{H}}, \\
w_{3}=w_{4}+\frac{\lambda_{H} \tau c}{r+\lambda_{H} r}, \quad w_{4}=(1-\tau)\left(K_{H}-\frac{y_{H}+\lambda_{H} \alpha_{L} K_{L}}{r-\mu+\lambda_{H}}\right) x_{L}^{*} \\
w_{5}=\left(\lambda_{L}+\lambda_{H}\right)\left(x_{L}^{*}\right)^{\gamma}, \quad w_{6}=\left(x_{L}^{*}\right)^{\beta_{2}}-\left(x_{H}^{*}\right)^{\beta_{2}}\left(\frac{x_{L}^{*}}{x_{H}^{*}}\right)^{\beta_{1}}, \\
w_{7}=\left(\xi \lambda_{L}+\gamma \lambda_{H}\right)\left(x_{L}^{*}\right)^{\gamma}, \quad w_{8}=\beta_{2}\left(x_{L}^{*}\right)^{\beta_{2}}-\beta_{1}\left(x_{H}^{*}\right)^{\beta_{2}}\left(\frac{x_{L}^{*}}{x_{H}^{*}}\right)^{\beta_{1}}
\end{gathered}
$$

The expressions reported in Proposition 2 for the levered firm value are similar to those provided for the value of corporate debt (Proposition 1) and, thus, admit a similar interpretation. Total firm value is equal to the sum of the value of a perpetual entitlement to the current flow of income and the change in value that occurs either after a change in 
the value of the aggregate shock or when the idiosyncratic shock reaches a boundary $x_{i}^{*}$. As was the case for the value of corporate debt, the default threshold is chosen solely by shareholders and hence is an exogenous parameter for firm value.

\subsection{Equity value and default policy}

Because the values of corporate securities depend on the default threshold selected by shareholders, we now turn to the valuation of equity. Based on the closed-form solution for equity value, we will derive the equity value-maximizing default policy.

\subsubsection{Equity value}

In the absence of arbitrage, levered firm value equals the sum of the debt and equity values. Formally, $v_{i}(\cdot) \equiv d_{i}(\cdot)+e_{i}(\cdot)$ for $i=L, H$. This simple observation permits the following result.

Proposition 3. When the firm's operating cash flows are given by Eq. (1) and the firm has issued finite-maturity debt with contractual coupon payment $c$, instantaneous debt retirement rate $m$, and total principal $p$, the value of equity in regime $i=L, H$ is given by

$$
e_{L}(x, c, m, p)= \begin{cases}v_{L}(x, c)-d_{L}(x, c, m, p), & x \geqslant x_{L}^{*}, \\ 0, & x \leqslant x_{L}^{*},\end{cases}
$$

and

$$
e_{H}(x, c, m, p)= \begin{cases}v_{H}(x, c)-d_{H}(x, c, m, p), & x \geqslant x_{L}^{*}, \\ v_{H}(x, c)-d_{H}(x, c, m, p), & x_{H}^{*} \leqslant x \leqslant x_{L}^{*}, \\ 0, & x \leqslant x_{H}^{*},\end{cases}
$$

where the endogenous default thresholds $x_{L}^{*}$ and $x_{H}^{*}$ are reported in Proposition 4 and $d_{i}(\cdot)$ and $v_{i}(\cdot)$ in regime $i=L, H$ are given in Propositions 1 and 2 , respectively.

The expressions in Proposition 3 for the value of equity are similar to those for firm value (Proposition 2) and, thus, admit a similar interpretation. Since debt and firm value functions individually satisfy the appropriate value-matching conditions in Eqs. (14)-(15) and Eqs. (29)-(30), equity value, or $v_{i}(\cdot)-d_{i}(\cdot)$, also satisfies the corresponding valuematching conditions. Likewise, because the debt and firm value functions are derived based upon the appropriate continuity and smoothness conditions in Eqs. (16)-(17) and Eqs. (31)-(32),), equity value satisfies boundary conditions of this type too. Given the abandonment value function of the firm, equity value equals zero in case of both smooth and sudden default when the absolute priority rule is enforced (see Morellec, 2001). The main difference between firm (or debt) and equity is that the default threshold is determined by shareholders and, hence, only depends on equity value.

\subsubsection{Default policy}

Once debt has been issued, the shareholders' only decision in the static model is to select the default policy that maximizes the value of equity. Within our model, markets are frictionless and default is triggered by shareholders' decision to optimally cease injecting funds in the firm (see also Leland, 1998; Duffie and Lando, 2001; Morellec, 2004). Formally, an equity value-maximizing default policy in our framework is associated with 
the following two boundary conditions:

$$
\begin{aligned}
e_{L}^{\prime}\left(x_{L}^{*}, c, m, p\right) & =0, \\
e_{H}^{\prime}\left(x_{H}^{*}, c, m, p\right) & =0,
\end{aligned}
$$

where derivatives are taken with respect to $x$. The smooth-pasting (39) and (40) ensure that default occurs along the optimal path by requiring a continuity of the slopes at the endogenous default thresholds $x_{L}^{*}$ and $x_{H}^{*}$. By combining the results from Propositions 1-3 with equity holders' optimality conditions in (39)-(40), we obtain closed-form expressions for the endogenous default thresholds reported in Proposition 4.

Proposition 4. When the firm's operating cash flows are given by Eq. (1), the default policy that maximizes equity value in regime $i=L, H$ is given by a trigger-strategy $x_{i}^{*}$. That is, if there exist non negative solutions to the following non linear equations

$$
\begin{aligned}
& w_{1} \xi-\bar{w}_{1} \bar{\xi}+(1-\tau) K_{l} x_{L}^{*}=\lambda_{L}\left[(\gamma-\xi) B\left(x_{L}^{*}\right)^{\gamma}-(\bar{\gamma}-\bar{\xi}) \bar{B}\left(x_{L}^{*}\right)^{\bar{\gamma}}\right], \\
& w_{2} \beta_{1}-\bar{w}_{2} \bar{\beta}_{1}+\frac{(1-\tau) y_{H}}{r-\mu+\lambda_{H}} x_{H}^{*}=\left(\beta_{1}-\beta_{2}\right) D\left(x_{H}^{*}\right)^{\beta_{2}}-\left(\bar{\beta}_{1}-\bar{\beta}_{2}\right) \bar{D}\left(x_{H}^{*}\right)^{\bar{\beta}_{2}},
\end{aligned}
$$

where $w_{1}, \bar{w}_{1}, w_{2}, \bar{w}_{2}, \bar{B}, \bar{D}, B$, and $D$ are given in Eqs. (27)-(28) and Eqs. (41)-(42), then the equity value-maximizing default policy is characterized by the default thresholds $x_{L}^{*} \equiv R x_{H}^{*}$ and $x_{H}^{*}$ that solve the above two equations.

As in standard contingent claims models, the default policy that maximizes equity value balances the present value of the cash flows that shareholders receive in continuation with the cash flow that they receive in liquidation. The present value of a perpetual entitlement to the (pre-tax) cash flows to shareholders in state $i$ and at time $t$ is given by $K_{i} x-(c+m p) /(r+m)$. Therefore, for a given debt policy $(c, m, p)$, the default threshold should decrease with those parameters that increase $K_{i}$. At the same time, the decision to default should be hastened by larger opportunity costs of remaining active. Hence the default thresholds increase with the debt coupon $c$ and the debt principal $p$, and decrease with average debt maturity $\bar{T}=1 / \mathrm{m}$.

To better understand the mechanics of default, consider the case of infinite maturity debt where $m=0$. In this case, the equity value-maximizing default threshold is linearly increasing in the debt service flow $c$ in each regime $i$ (see Appendix B). This default policy implies that it is possible to represent, for each regime $i$, the no-default and default regions as in Fig. 1a. In the no-default region $\left[x_{i}^{*}, \infty\right)$, the value of waiting to default exceeds the default payoff and it is optimal for shareholders to inject funds into the firm. In the default region $\left(0, x_{i}^{*}\right]$, the default payoff exceeds the present value of cash flows in continuation and hence it is optimal for shareholders to default.

The region $\left[x_{H}^{*}, x_{L}^{*}\right]$, where default occurs if the value of the aggregate shock changes from $y_{H}$ to $y_{L}$, can then be represented as in Fig. 1b. This figure reveals that while the optimal default policy corresponds to a trigger policy when the economy is in a boom, this is not the case when it is in a contraction. In this second state, there are two ways to trigger default. First, the value of the idiosyncratic shock can decrease to the default threshold $x_{L}^{*}$. This is the default policy that is described in standard models of the levered firm. Second, there can be a change in the value of the aggregate shock from $y_{H}$ to $y_{L}$ while the value of the idiosyncratic shock belongs to the region $\left[x_{H}^{*}, x_{L}^{*}\right]$. We show below that these two ways to trigger default have different implications at the aggregate level. 


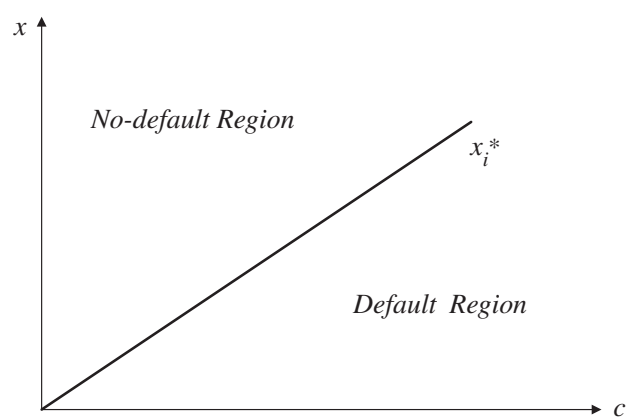

(a)

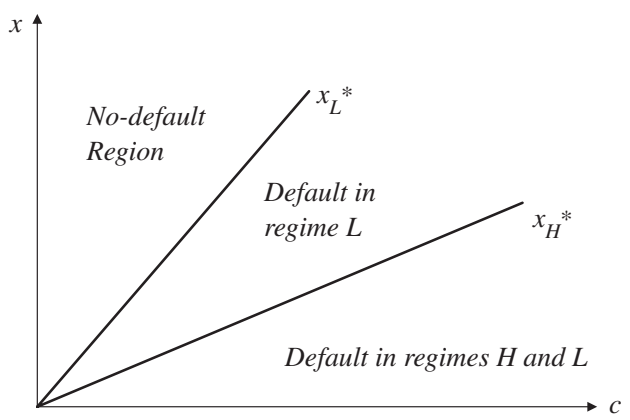

(b)

Fig. 1. Optimal default policy. (a) Represents the equity value-maximizing default policy for $m=0$ in each regime $i$ as a function of $c$. This default policy requires the firm to default on its debt obligations the first time $x_{t}$ reaches $x_{i}^{*}$. (b) Represents the impact of a change in macroeconomic conditions on the value-maximizing default policy. There exists a region for the state variable $x$ for which a shift from the expansion regime to the contraction regime triggers default.

\section{Empirical predictions}

\subsection{Calibration of parameters}

This section examines the empirical predictions of the model for the decision to default, value-maximizing financing policies, and credit spreads on corporate debt. To determine asset prices and capital structure decisions, we need to select parameter values for the initial value of the firm's assets $x_{0}$, the risk free interest rate $r$, the tax advantage of debt $\tau$, the recovery rate $\alpha_{i}$, the volatility of the firm's income $\sigma$, the growth rate of cash flows $\mu$, and the persistence in regimes $\lambda_{L}$ and $\lambda_{H}$. In what follows, we select parameter values that roughly reflect a typical S\&P 500 firm. Table 1 summarizes our parameter choices.

Consider first the parameters governing operating cash flows. We set the initial value of these cash flows to $x_{0}=1$. While this value is arbitrary, we show below that neither optimal leverage ratios nor credit spreads at optimal leverage depend on this parameter. The risk free rate is taken from the yield curve on Treasury bonds. The growth rate of cash flows has been selected to generate a payout ratio consistent with observed payout ratios. The firm's payout ratio reflects the sum of the payments to both bondholders and shareholders. Following Huang and Huang (2002), we take the weighted averages between the average dividend yields (4\% according to Ibbotson and Associates) and the average historical coupon rate (close to $9 \%$ ), with weights given by the median leverage ratio of S\&P 500 firms (approximately 20\%). In our model, the firm's payout ratio in regime $i$ is given by $\left((1-\tau) x y_{i}+\tau c_{i}\right) / v_{i}\left(x, c_{i}\right)$, where $c_{i}$ is the coupon payment in regime $i$. In the base case, the predicted payout is $2.35 \%$ in regime $L$ and $6.85 \%$ in regime $H$. Weighting those values by the fraction of the time spent in each regime gives an average payout ratio of: $0.4 \times 2.35+0.6 \times 6.85=5.05 \%$. Similarly, the value of the volatility parameter is chosen to match the (leverage-adjusted) asset return volatility of an average S\&P 500 firm's equity return volatility.

The tax advantage of debt captures corporate and personal taxes and is set equal to $\tau=0.15$. Liquidation costs (in percentage) are defined as the firm's going concern value minus its liquidation value, divided by its going concern value, which is measured by $1-\alpha$ 
Table 1

Parameter choices

\begin{tabular}{ll}
\hline risk free interest rate & $r=0.055$ \\
initial level of cash flow & $x_{0}=1$ \\
growth rate of cash flows & $\mu=0.005$ \\
volatility of cash flows & $\sigma=0.25$ \\
tax advantage of debt & $\tau=0.15$ \\
recovery rate on assets & $\alpha_{H}=\alpha_{L}=0.6$ \\
persistence of shocks & $\lambda_{L}=0.15, \lambda_{H}=0.1$ \\
average debt maturity & $\bar{T}=5(m=0.2)$
\end{tabular}

within our model. Using this definition, Alderson and Betker (1995) and Gilson (1997) respectively report liquidation costs equal to $36.5 \%$ and $45.5 \%$ for the median firm in their samples. We simply take the average, which is about $40 \%$. This asset recovery rate implies an expected recovery rate of $50 \%$ on debt principal, which is close to the historical average reported by Hamilton et al. (2003).

The maturity of corporate debt is chosen to reflect the average maturity of corporate bonds as reported by Barclay and Smith (1995) and Stohs and Mauer (1996). Thus, we take $\bar{T}=5$ in our base case. The persistence parameter values reflect the fact that expansions are of longer duration than recessions. Importantly, the relative increase in the present value of future cash flows following a shift from the contraction regime to the expansion regimes is equal to

$$
\frac{A_{H}(x)-A_{L}(x)}{A_{L}(x)}=\frac{(r-\mu)\left(y_{H}-y_{L}\right)}{\lambda_{L} y_{H}+\lambda_{H} y_{L}+(r-\mu) y_{L}}=20 \% .
$$

Thus, our base case environment calls for reasonable variations of policy choices across regimes. In addition, these input parameter values imply a ratio of the default rate in a recession versus a boom between 5 and 7.5 , which is consistent with US historical data as reported by Altman and Brady (2001).

Finally, we have reported formulas for asset prices, given a coupon $c$ and a principal value $p$. When debt is first issued, there is an additional constraint relating the market value of corporate debt to its principal: for a given degree of leverage, the coupon $c$ is set so that market value $d_{i}(\cdot)$ equals principal value $p$ in regime $i=L, H$.

\subsection{The decision to default}

We start by analyzing shareholders' default decision. As we show in Section 3, when the default decision is endogenous, the default threshold selected by shareholders depends on the parameters determining the firm's environment and there exists one default threshold per regime. Moreover, default thresholds are countercyclical, leading to higher default rates in recessions. In particular, we show in the Appendix that, when $m=0$, we can write the default threshold in the expansion regime as

$$
K_{H} x_{H}^{*}=\frac{c}{r} \Gamma
$$




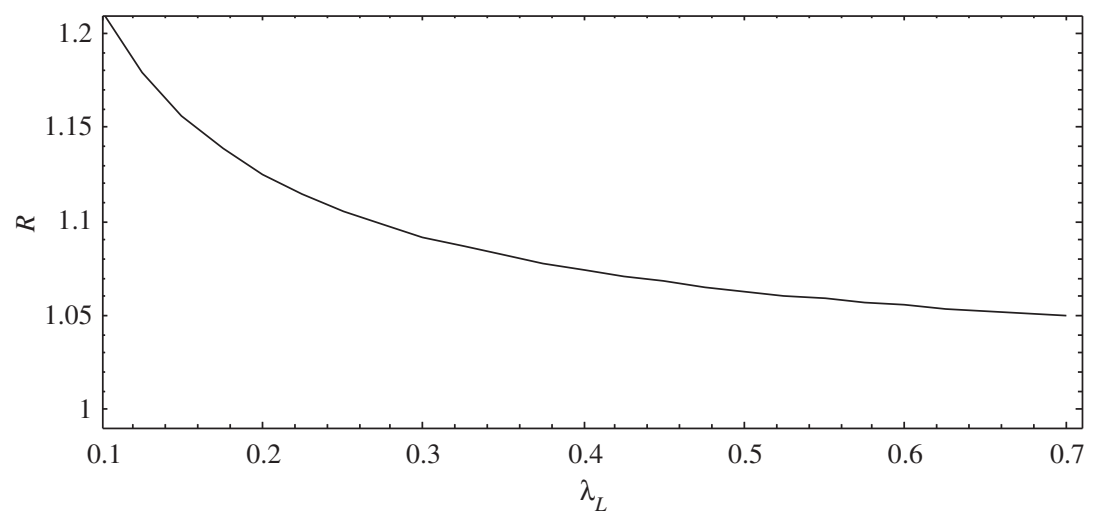

Fig. 2. Default thresholds ratio. It plots the ratio $R=x_{L}^{*} / x_{H}^{*}$, which relates the default thresholds in the two regimes as a function of the persistence of cash flows in the contraction regime $\lambda_{L}$. Input parameter values are set as in the base case environment and debt is initially issued in the expansion regime. In addition, we presume that the coupon level is $c=0.2$ and that $\lambda_{L} \in[0.1,0.7]$.

where $\Gamma$ is a positive constant and

$$
K_{H} x_{H}^{*}=E\left[\int_{t}^{\infty} \mathrm{e}^{-r u} x_{t+u} y_{t+u} \mathrm{~d} u \mid x_{t}=x_{H}^{*}, y_{t}=y_{H}\right] .
$$

These equations reveal that shareholders default on the firm's debt obligations when the present value of future cash flows equals the adjusted opportunity cost of remaining active. The adjustment is made through the factor $\Gamma$, which represents the option value of waiting to default. A similar argument applies to the default decision in the recession regime.

Another interesting feature of the optimal default policy is that, because of the possibility of a regime shift, the default thresholds $x_{L}^{*}$ and $x_{H}^{*}$ are related to one another. Specifically, the equity value-maximizing default strategy is characterized by a different default threshold in each regime. Moreover, because of the possibility of a regime shift, each default threshold takes into account the optimal default threshold in the other regime. This functional dependence is captured by the ratio $R$ of the two default thresholds. Two factors are essential in determining the magnitude of this ratio: (1) the ratio of cash flows in the expansion versus contraction regimes $y_{H} / y_{L}$, and (2) the persistence in regimes $\lambda_{L}$ and $\lambda_{H}$. In particular, the ratio of the two default thresholds increases with $y_{H} / y_{L}$. In addition, because the persistence in regimes represents the opportunity cost of defaulting in one regime versus the other, an increase in $\lambda_{i}$ reduces the opportunity cost of defaulting in regime $i$, and hence narrows the gap between the default thresholds in the two regimes. This effect is illustrated by Fig. 2, which plots the ratio of the two default thresholds as a function of the persistence parameter in the contraction regime $L$.

Importantly, the two default thresholds $x_{L}^{*}$ and $x_{H}^{*}$ exceed the default threshold associated with a one-regime model that would be calibrated during an expansion (i.e.with $\lambda_{H}=0$ and $y_{t}=y_{H}$ for all $\left.t \geqslant 0\right) .{ }^{6}$ This feature of the model is represented in Fig. 3, which

\footnotetext{
${ }^{6}$ This follows from the following arguments. Let $\mathrm{e}^{H}(x, c)$ denote equity value for the one-regime model with $y_{t}=y_{H}$ for all $t$. Then, equation When the firm's operating cash flows are given by Eq. (45) implies that $e_{i}(x, c)<\mathrm{e}^{H}(x, c), i=H, L$. Thus, the value matching condition implies that $0=e_{i}\left(x_{i}^{*}, c\right)<\mathrm{e}^{H}\left(x_{i}^{*}, c\right)$. Since $\mathrm{e}^{H}(x, c)$
} 


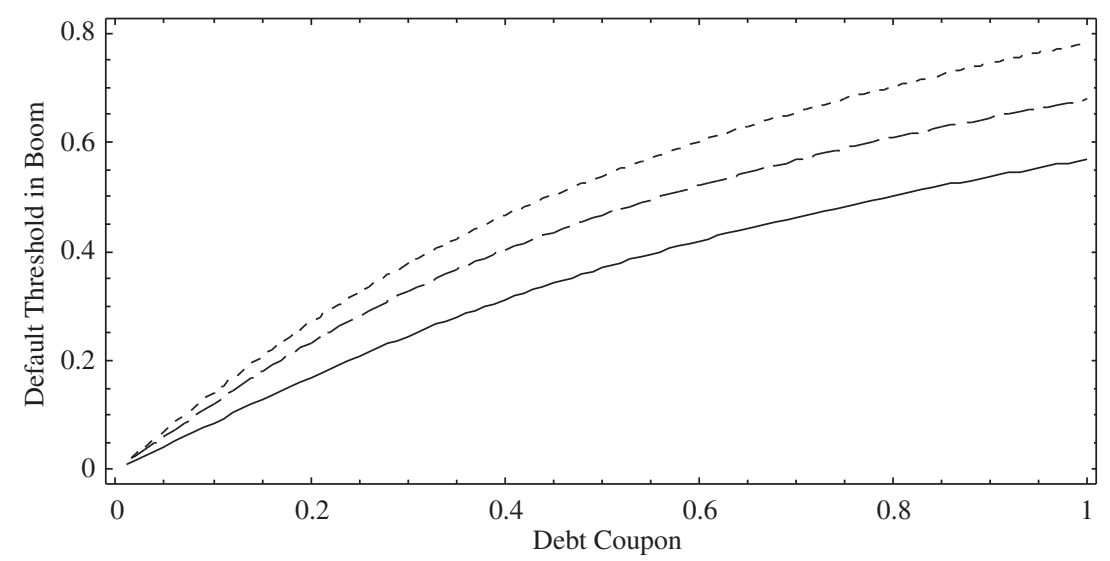

Fig. 3. Default thresholds in the two- vs. one-regime models. It plots the two default thresholds that obtain in our model as well as the default threshold $x_{\text {exp }}^{*}$ that would obtain in a standard model calibrated in the expansion regime as a function of the coupon payment. The short-dashed line, the long-dashed line, and the solid line, respectively, represent $x_{L}^{*}, x_{H}^{*}$, and $x_{\mathrm{exp}}^{*}$. Input parameter values are set as in the base case environment. The coupon payment varies between zero and one.

plots the selected default thresholds as a function of the coupon payment $c$. Because the probability of default is increasing in the default threshold, Fig. 3 implies that the two-regime model is associated with estimates of the probability of default that are (1) higher than those associated with the one regime model calibrated in a boom and (2) lower than those associated with the one regime model calibrated in a recession. This finding has several important implications for financial institutions. First, as noted by Allen and Saunders (2002), previous “models' overly optimistic estimates of default risk during boom times reinforces the natural tendency of banks to overlend just at the point in the business cycle that the central bank prefers restraint." Our model shows that by recognizing the impact of macroeconomic cycles, a simple two-regime model can help mitigate this effect. Second, because credit risk models also determine the amount of reserves of capital a bank should hold (and hence the amount of capital a bank can allocate to the real side of the economy), our model should also mitigate the cyclical cash constraint effects that show up in the lending process by reducing the estimates of the probability of default when the economy is in a recession.

While some of the above arguments are familiar from the contingent claims literature, the present model delivers a richer set of default policies than do traditional contingent claims models. Notably, when the aggregate shock can shift between discrete states at random times, default by firms in a common market or industry can arise simultaneously (see also Giesecke, 2002; Driessen, 2005; Cremers et al., 2005). This clustering of defaults will happen when the idiosyncratic shock of several firms belongs to the transient region and the aggregate shock shifts from $y_{H}$ to $y_{L}$ (thereby triggering an immediate default of these firms). Importantly, in the standard model with a single risk factor, a clustering of defaults is unlikely to occur with the sequential exercise of options to default, unless firms

(footnote continued)

is increasing in $x$, it follows that the default threshold for the one regime model with $y_{t}=y_{H}$ must be lower than $x_{i}^{*}$. Similarly, one can show that the default threshold for the one regime model with $y_{t}=y_{L}$ is higher than $x_{i}^{*}$. 
are identical. However, a standard diffusion model with stochastic volatility as a second aggregate risk factor could also be used to model joint defaults. In our model the aggregate risk factor can only take two values, and hence implies a common systemic jump to default.

\subsection{Optimal leverage and debt capacity}

We now turn to the analysis of leverage decisions. Within our setting, the leverage ratio is defined by

$$
L_{i}(x, c, m, p) \equiv \frac{d_{i}(x, c, m, p)}{v_{i}(x, c)}, \quad i=L, H .
$$

While default policy is selected by shareholders to maximize equity after the issuance of corporate debt (and hence maximizes $e_{i}(\cdot)$ ), debt policy maximizes $e_{i}(\cdot)$ plus the proceeds from the debt issue, i.e. $v_{i}(\cdot) \equiv e_{i}(\cdot)+d_{i}(\cdot)$ for $i=L, H$. Because firm value depends on the current regime, the selected coupon rate and leverage ratio also depend on the current regime. The coupon rate selected by shareholders is the solution to the problem: $\max _{c} v_{i}(x, c)$. Denote the solution to this problem by $c_{i}^{*}(x)$. We assume that this solution is unique and verify this conjecture in the simulations. Optimal leverage then equals $L_{i}^{*}(x, m, p) \equiv L_{i}\left(x, c_{i}^{*}(x), m, p\right)$. In the simulations below we compute optimal leverage assuming that the recovery rate does not depend on the regime.

In the base case environment, the value-maximizing leverage ratio is equal to $19.72 \%$ in a recession and $16.61 \%$ in a boom. Thus, within our model, leverage is countercyclical. This feature of the model is consistent with the evidence reported by Korajczyk and Levy (2003). The countercyclical nature of leverage results from two countervailing effects. First, regime shifts affect the firm's default risk. Second, regime shifts change the present value of future cash flows. In particular, the coupon rate, which determines the book value of debt, in the expansion regime exceeds the coupon rate in the contraction regime, reflecting the additional debt capacity associated with a lower default risk. At the same time, however, the present value of future cash flows is greater in the expansion regime, increasing the denominator of Eq. (46). In our model, the second effect always dominates the first, generating the countercyclicality in leverage. ${ }^{7}$ Importantly, the fact that the coupon is regime dependent alleviates somewhat the difference between default thresholds and debt capacities in booms versus recessions (see below).

Because firm value depends on the various dimensions of the firm's environment, so does the leverage ratio selected by shareholders. Consider, for example, the impact of volatility on the firm value-maximizing leverage ratio. In contingent claims models of the levered firm, the volatility parameter provides a measure of bankruptcy risk. This in turn implies that this parameter affects both expected bankruptcy costs and the tax advantage of debtthe greater volatility, the shorter the time period over which the firm benefits from the tax shield. Since optimal capital structure reflects a trade-off between these two quantities (recall that in our model investment policy is fixed), optimal leverage depends crucially on the level of the volatility parameter. In particular, an increase in volatility typically raises

\footnotetext{
${ }^{7}$ Given that we assume the default-riskfree interest rate is constant, it would be potentially interesting, but technically challenging, to extend our regime-switching model to procyclical variations in interest rates. Inutitively, a procyclical interest rate process should attenuate the present value effect.
} 
Table 2

\begin{tabular}{lllll}
\hline & $\begin{array}{l}\text { Contraction } \\
\text { coupon }\end{array}$ & $\begin{array}{l}\text { Regime } \\
\text { leverage }\end{array}$ & $\begin{array}{l}\text { Expansion } \\
\text { coupon }\end{array}$ & $\begin{array}{l}\text { Regime } \\
\text { leverage }\end{array}$ \\
\hline Base & 0.1196 & 19.72 & 0.1206 & 16.61 \\
$\sigma=0.20$ & 0.1513 & 24.97 & 0.1523 & 21.03 \\
$\sigma=0.30$ & 0.0958 & 15.70 & 0.0967 & 13.24 \\
$\lambda_{L}=0.10$ & 0.1064 & 19.91 & 0.1082 & 15.98 \\
$\lambda_{L}=0.20$ & 0.1289 & 19.57 & 0.1295 & 17.02 \\
$\bar{T}=3$ & 0.0910 & 15.31 & 0.0913 & 12.83 \\
$\bar{T}=7$ & 0.1453 & 23.39 & 0.1473 & 19.83 \\
\hline
\end{tabular}

default risk and hence reduces the value-maximizing debt ratio. Table 2 provides comparative statics that show the impact of volatility on the quantities of interest. Data in Table 2 and Fig. 4 reveal that the selected coupon rate and leverage ratio are very sensitive to the values of the volatility parameter. For example, as volatility increases from $20 \%$ to $30 \%$, optimal leverage in the expansion regime decreases from $21.03 \%$ to $13.24 \%$.

Consider next the impact of persistence in regimes on financing decisions. Numerical results in Table 2 indicate that the persistence in regimes is an important determinant of value-maximizing financing policies. For example, as $\lambda_{L}$, an indicator of the nonpersistence of regime $L$, increases from 0.1 to 0.2 , it is optimal for shareholders to increase the optimal coupon payment in regime $L$ by $21 \%$ (from 0.1064 to 0.1289 ). Data in Table 2 and Fig. 4 also reveal that an increase in $\lambda_{i}$ decreases optimal leverage since firm value itself depends on persistence in regimes. Because of the very nature of the model, a change in $\lambda_{i}$ affects quantities in both regimes. Maturity also has a significant impact on financing decisions. In our model, a reduction in the maturity of the debt contract implies an increase in the debt service and thus an increase in the probability of default. The optimal response for the firm is to issue less debt. Simulation results reported in Table 2 show for example that as the average debt maturity $\bar{T}$ decreases from seven to three years, the firm optimally reduces its leverage ratio from $19.8 \%$ to $12.8 \%$ in the expansion regime. Finally, and as illustrated by Fig. 4, other standard comparative statics apply within our model, so we do not report them.

An alternative expression for the variations in debt policy that may arise because of changes in macroeconomic conditions relates to their impact on the firm's debt capacity. In this paper, we define debt capacity as the maximum amount of debt that can be sold against the firm's assets. Arguably, if default clusters can arise in a recession, the expected recovery rate on the firm's assets is likely to be lower than the expected recovery rate in a boom since the industry peers are likely to be experiencing problems themselves (see Shleifer and Vishny (1992) for a theoretical argument and Acharya et al. (2003) for evidence). Thus, we report in Fig. 5 the debt capacity of the firm for different recovery rates in a recession. Because default risk is lower in an expansion than in a contraction, the debt capacity of the firm is greater when the economy is in an expansion. In the base case environment for example, the maximum value of corporate debt that could be sold in a boom is $15 \%$ larger than the maximum value that could be sold in a contraction. As the recovery rate in the contraction regime decreases, this difference between regimes increases and exceeds $40 \%$ when $\alpha_{L}=0.2$. 

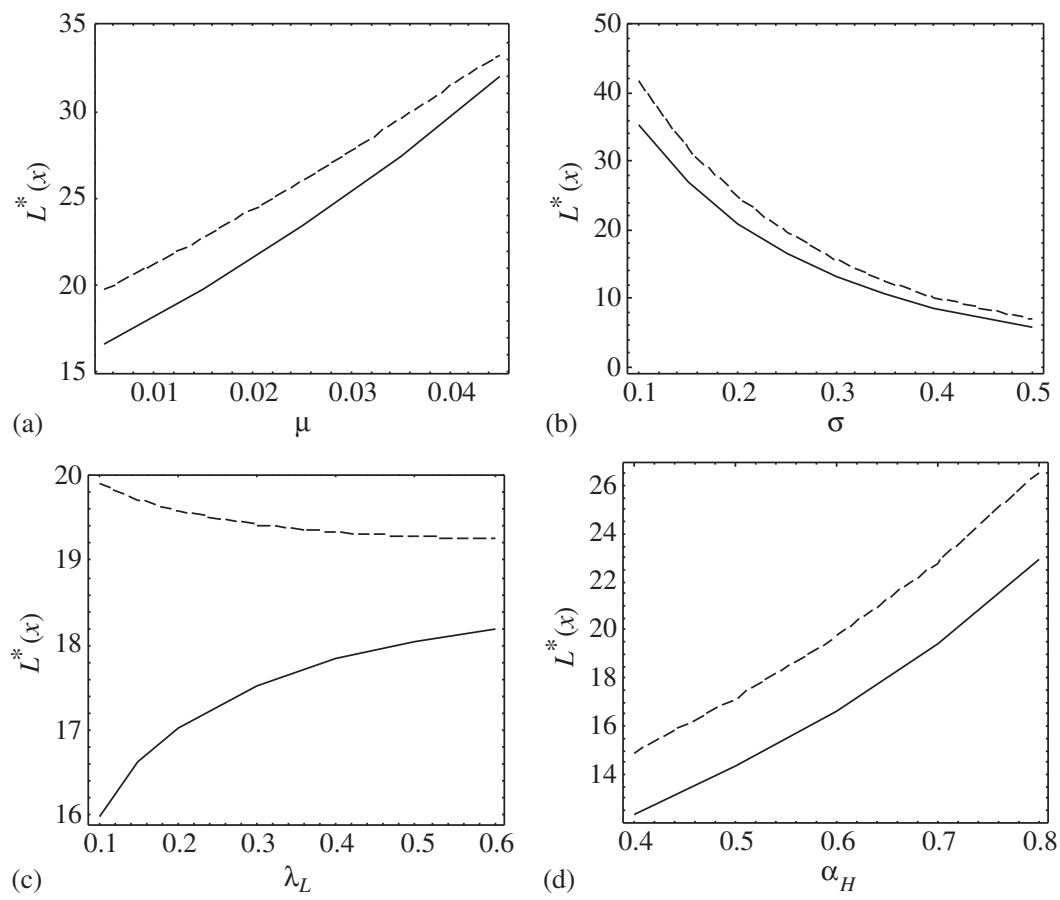

Fig. 4. Optimal leverage ratios. It plots the optimal leverage ratio of the firm as a function of: (1) the growth rate of cash flows $\mu$; (2) the volatility of cash flows $\sigma$; (3) the persistence of recessions $\lambda_{L}$; and (4) the recovery rate $\alpha_{H}$. The solid line represents optimal leverage in a boom and the dashed line optimal leverage in a recession. (a) Leverage and growth rate. (b) Leverage and volatility. (c) Leverage and persistence. (d) Leverage and recovery rate.

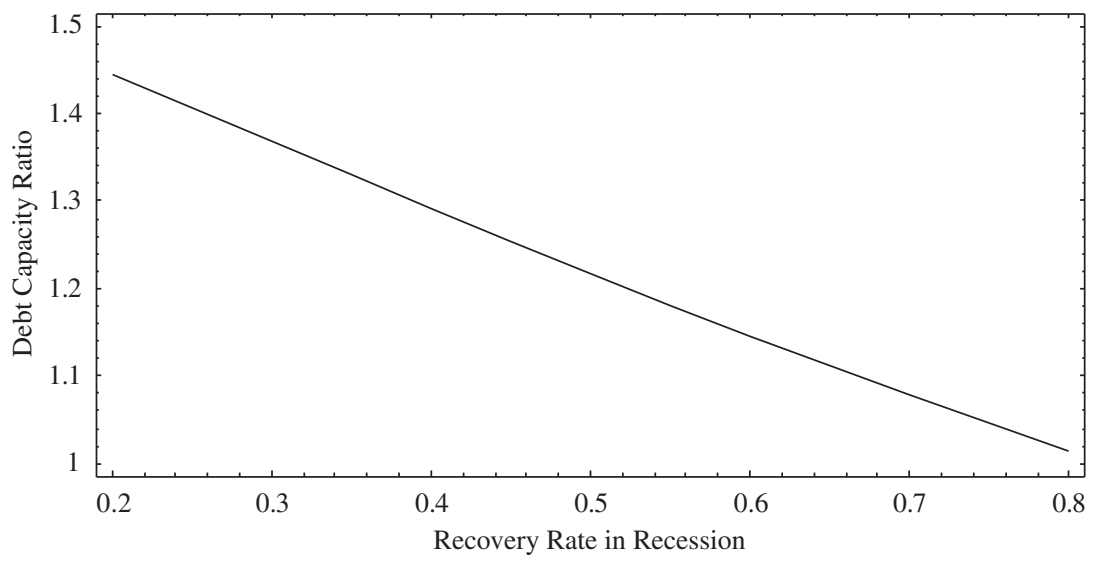

Fig. 5. Debt capacity. It plots the ratio of the debt capacity in a boom to the debt capacity in a contraction as a function of the recovery rate in the contraction regime. Debt capacity is defined as the maximum amount of debt that the firm can float. 

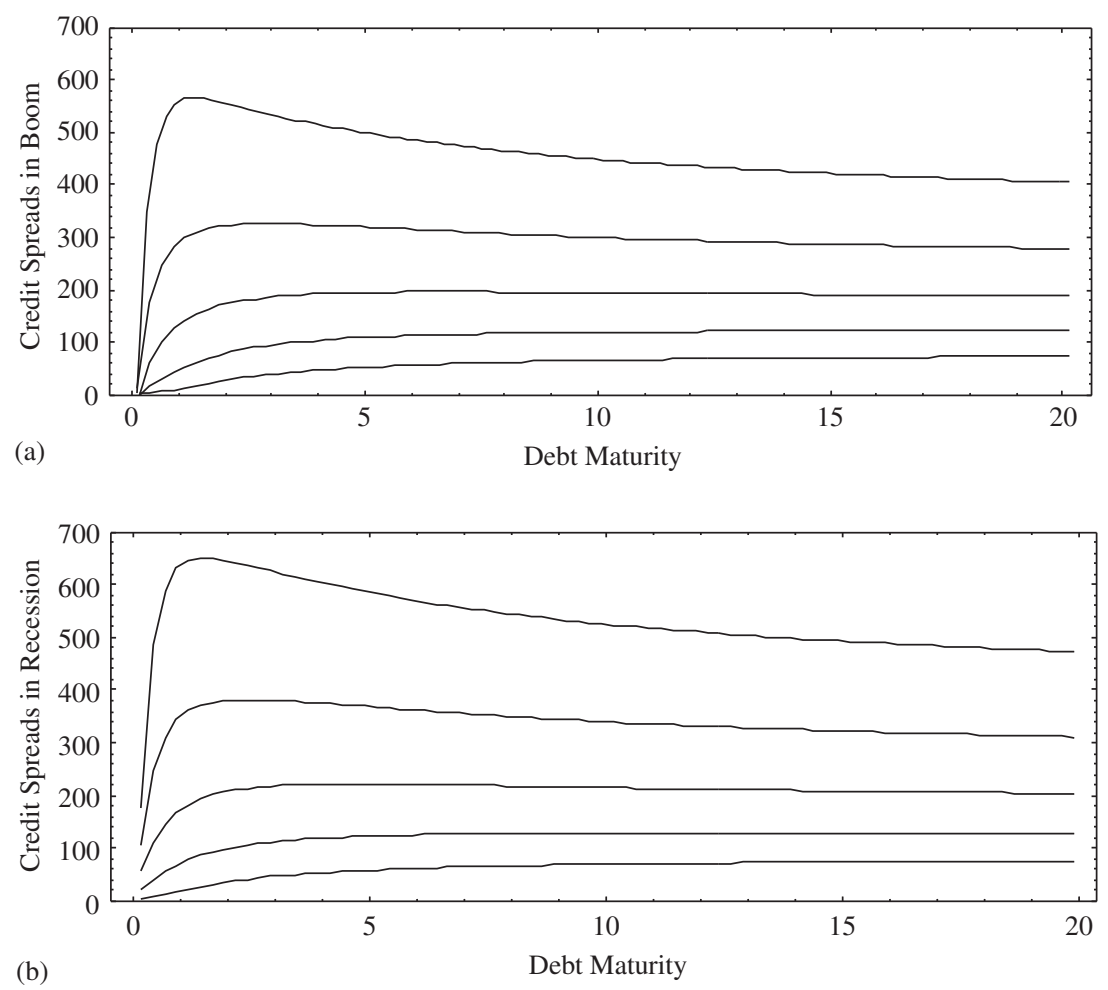

Fig. 6. Term structure of credit spreads. (a) and (b) plot the term structure credit spreads on corporate debt. The five lines represent credit spreads resulting from leverage ratios of $30 \%, 40 \%, 50 \%, 60 \%$, and $70 \%$ in a boom. We use the same debt structure $(c, m, p)$ to compute spreads in a recession. (a) Term structure of credit spreads in a boom. (b) Term structure of credit spreads in a recession.

\subsection{Term structure of credit spreads}

We now turn to the analysis of credit spreads on corporate debt. Credit spreads on newly issued debt are measured by the following expression:

$$
c s_{i}(x, c, m, p)=\frac{c}{d_{i}(x, c, m, p)}-r .
$$

Fig. 6 examines the credit spread on newly issued debt as a function of average debt maturity $\bar{T}$, for alternative leverage ratios when the recovery rate does not depend on the regime. For highly levered firms, credit spreads are high, but decrease as the average debt maturity $\bar{T}$ increases beyond one year. For medium-to-high leverage ratios, credit spreads are hump-shaped. That is, intermediate-term debt promises higher yields than either shortor long-term corporate debt. Credit spreads of low leverage firms are low, but increase with maturity $\bar{T}$.

In contrast to previous contingent claims models, our framework can produce non trivial credit spreads for short-term corporate debt issues (see also Duffie and Lando, 2001; Zhou, 2001). In the base case environment, credit spreads are relatively close to zero for 

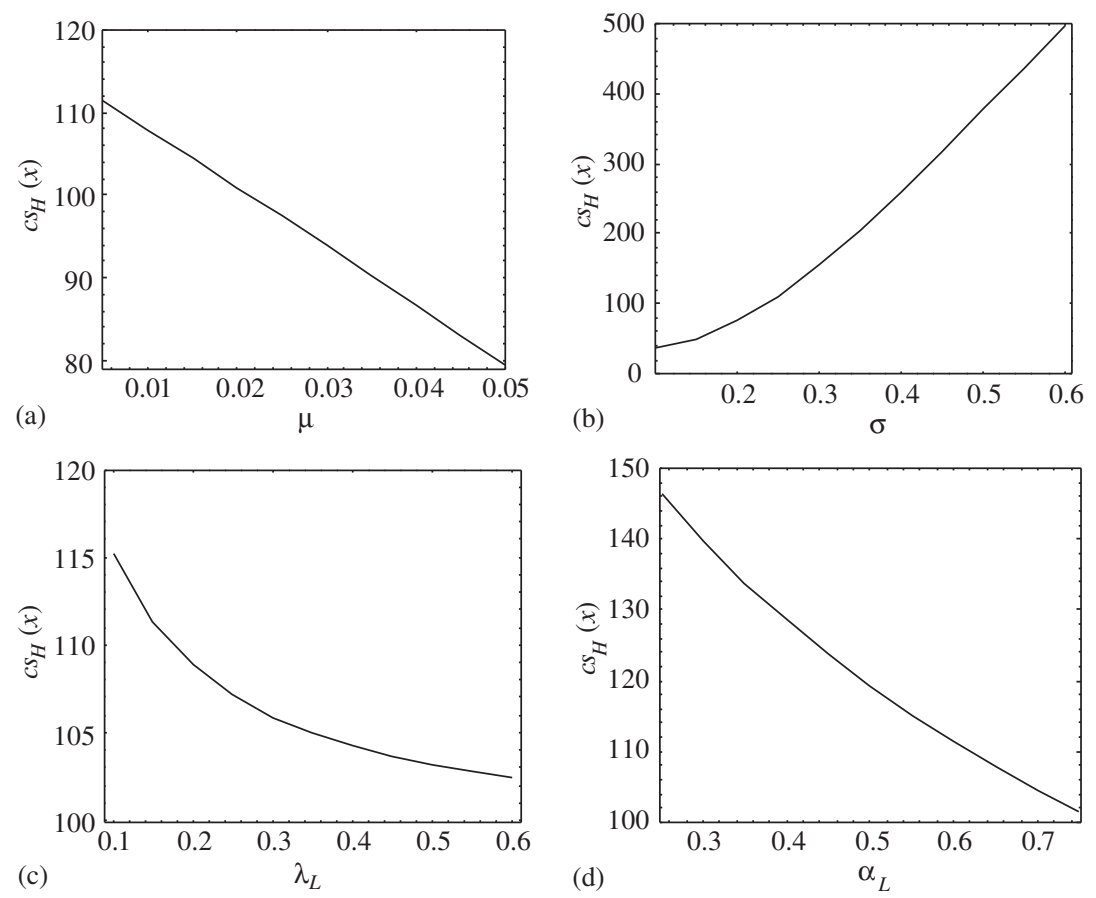

Fig. 7. Credit spreads. It plots credit spreads on corporate debt for a leverage of $40 \%$ as a function of: (1) the growth rate of cash flows $\mu$; (2) the volatility of cash flows $\sigma$; (3) the persistence of recessions $\lambda_{L}$; and (4) the recovery rate $\alpha_{L}$. Input parameter values are set as in the base case environment: (a) Credit spreads and growth rate. (b) Credit spreads and volatility. (c) Credit spreads and persistence. (d) Credit spreads and recovery rate.

short-term debt when the economy is in a boom. However, in a recession very short-term credit spreads taper off at around 20-200 basis points in case of medium to high leverage. As a result, the slope of the term structure is steeper at the short end in booms than in recessions. This result obtains because with regime shifts investors are always more uncertain about the nearness of default. The figure also reveals that in a recession, credit spreads on debt exceed those prevailing during a boom by up to 150 basis points.

Let us now turn to analyzing the determinants of credit spreads. Consider first volatility. Fig. 7 indicates that credit spreads increase with the volatility of cash flows from assets in place. Within the present model, volatility has two effects on credit spreads. First, for a given coupon payment, the probability of default and, hence the cost of debt, increases with the volatility parameter $\sigma$. Second, because the cost of debt increases with $\sigma$, the optimal response for shareholders typically is to issue less debt. Numerical results indicate that the first effect dominates, so that credit spreads increase with volatility.

Consider next the growth rate of cash flows. Again, the impact of this parameter on credit spreads at optimal leverage results from two opposite effects. First, for a given coupon payment, the default threshold selected by shareholders decreases with $\mu$ and so do expected bankruptcy costs. Second, because the cost of debt decreases with $\mu$, it is optimal for shareholders to issue more debt. Numerical results reported in Fig. 7 indicate that the first effect dominates so that credit spreads decrease with the growth rate of cash flows. Numerical results also reveal that, because lower recovery rates imply a lower leverage 
level, credit spreads at optimal leverage levels increase when recovery rates decrease. (Obviously, for any given debt level credit spreads increase with liquidation costs.) Other standard comparative statics apply. Thus we do not report them.

\section{Dynamic capital structure}

In this section, we extend the basic model to allow for dynamic capital structure choice. To simplify the analysis, we presume throughout the section that $m=0$. In addition, we follow Fries et al. (1997) and Goldstein et al. (2001) by considering that the firm can only adjust its capital structure upwards. ${ }^{8}$ Specifically, we presume that there exists two thresholds $x_{H}^{U}$ and $x_{L}^{U}, x_{L}^{U}>x_{H}^{U}$, such that the firm increases its coupon payment once operating cash flows reach $y_{i} x_{i}^{U}$ in regime $i$. We also assume that whenever the firm issues debt, it incurs a proportional flotation cost $\imath$.

The scaling feature underlying our model permits the adoption of the dynamic capital structure formulation developed by Leland (1998) and Goldstein et al. (2001). To see this, observe that when $m=0$, the default thresholds $x_{H}^{*}$ and $x_{L}^{*}$ are linear in $c$. In addition, the optimal coupon rates $c_{H}^{*}$ and $c_{L}^{*}$ are also linear in $x .{ }^{9}$ This implies that if two firms $A$ and $B$ are identical except that their initial values of idiosyncratic shocks differ by a factor $x_{0}^{B}=\rho_{i} x_{0}^{A}$ in regime $i=H, L$, then the optimal coupon rate in regime $i, c_{i}^{B}=\rho_{i} c_{i}^{A}$, the optimal default threshold, $x_{i}^{* B}=\rho_{i} x_{i}^{* A}$, and every claim in regime $i$ will be larger by the same factor $\rho_{i}$. For the dynamic model, the scaling feature implies that since at the time of a restructuring the value of the idiosyncratic shock in regime $i, x_{i}^{U 1}=\rho_{i} x_{0}$, is a factor $\rho_{i}$ larger than its time 0 initial level $x_{0}$, it will be optimal to choose $c_{i}^{1}=\rho_{i} c_{i}^{0}, x_{i}^{D 1}=\rho_{i} x_{i}^{D 0}$, and $x_{i}^{U 1}=\rho_{i} x_{i}^{U 0}$, and all claims in regime $i$ will scale upward by the factor $\rho_{i}$.

We now use this scaling property of the model to solve for optimal dynamic capital structure. In our model firm value is equal to the value of unlevered assets plus the tax benefit of debt minus bankruptcy and flotation costs. Thus, we can write the value of the firm in regime $i$ as:

$$
v_{i}(x, c)=A_{i}(x)+T B_{i}(x, c)-B C_{i}(x, c)-\left(I C_{i}(x, c)+{ }_{\imath} P_{i}\right),
$$

where $T B_{i}(x, c)$ is the total tax benefit in regime $i, B C_{i}(x, c)$ are the total expected bankruptcy costs in regime $i,{ }_{l} P_{i}$ are the initial flotation costs in regime $i$, and $I C_{i}(x, c)$ is the present value of the flotation costs paid by the firm when restructuring its capital structure. Similarly, we can write the value of equity in regime $i$ as $e_{i}(x, c) \equiv$ $v_{i}(x, c)-D_{i}(x, c)$, where $D_{i}(x, c)$ is the value of debt in regime $i$. The default threshold

\footnotetext{
${ }^{8}$ The analysis can be extended to incorporate finite maturity debt and downward restructurings along the lines of Leland (1998). As discussed in Goldstein et al. (2001), while in theory management can both increase and decrease future debt levels, Gilson (1997) finds that transaction costs discourage debt reductions outside of Chapter 11. In addition, the fact that equity prices tend to trend upwards makes the option to issue additional debt more valuable than the option to repurchase outstanding debt. Finally, in this model (as in Leland, 1998), increasing maturity always increases firm value by increasing its debt capacity. Hence the optimal policy is to issue infinite maturity debt, i.e., to set $m=0$.

${ }^{9}$ This follows from the following arguments. Eqs. (B.3)-(B.6) in the Appendix imply that $A=c^{1-\xi} A^{\prime}, B=$ $c^{1-\gamma} B^{\prime}, C=c^{1-\beta_{1}} C^{\prime}, D=c^{1-\beta_{2}} D^{\prime}$, where $A^{\prime}, B^{\prime}, C^{\prime}$, and $D^{\prime}$ are independent of $c$. Thus, Eqs. (B.1)-(B.2) imply that $e_{H}$ and $e_{L}$ are homogeneous of degree one in $x$ and $c$. Similarly, debt values $d_{H}$ and $d_{L}$ are homogeneous of degree one in $x$ and $c$. This in turn implies that firm value has this homogeneity property in regime $i=H, L$. Therefore, the optimal coupon rate in regime $i$ is linear in $x$.
} 
selected by shareholders in regime $i$ satisfies the smooth-pasting condition

$$
e_{i}^{\prime}\left(x_{i}^{*}, c\right)=0
$$

where derivatives are taken with respect to $x$. Shareholders' objective is then to choose $c_{i}, \rho_{i}=x_{i}^{U} / x_{0}$ to maximize firm value subject to the above smooth-pasting condition and the requirement that debt is issued at par. That is, we allow the firm to choose different financing and restructuring strategies depending on the prevailing regime.

We report in Table 3 numerical results that rely on the solution presented in Appendix C when the value of the aggregate shock is $y_{H}$ (i.e., the expansion regime). As in Section 4, similar results with lower coupon payments and higher leverage ratios obtain in the contraction regime. Table 3 illustrates the following features of the dynamic model.

First, the possibility to adjust capital structure dynamically increases firm value and the associated gain decreases with the magnitude of flotation costs, as suggested by economic intuition. While the potential gain reported in Table 3 is low, this essentially results from a low tax benefit of debt in our base case environment. As the tax benefit of debt increases, the potential increase in firm value rises. For example, when the marginal corporate tax rate is $35 \%$ and flotation costs are $1 \%$, the value of the unlevered firm is 9.8 , the value of a levered firm following a static capital structure policy is 11.15 , and the value of a levered firm following a dynamic capital structure policy is 11.73 . Thus, the possibility of issuing debt increases firm value by $14 \%$ in the static model and by $20 \%$ in the dynamic model, compared with an unlevered firm.

A second interesting feature of the results reported in Table 3 is that the default thresholds in the dynamic model are always lower than the default thresholds in the static model. This feature results from two separate effects. First, the debt policy of the firm is more conservative in the dynamic model and thus the opportunity cost of remaining active is lower. Second, because of the options to increase leverage in the future, firm value is more valuable and it is thus optimal for shareholders to postpone the decision to default.

The third interesting feature of the data reported in Table 3 is that, consistent with economic intuition, the restructuring thresholds increase with flotation costs. In addition, because the tax advantage of debt is greater when $y_{t}=y_{H}$ than when $y_{t}=y_{L}$, the restructuring thresholds satisfy $x_{H}^{U}<x_{L}^{U}$. This result has several implications. First, it implies that firms should adjust their capital structure more often in booms than in recessions since the expected time between restructurings is decreasing with the value of the restructuring threshold. Second, it also implies that, holding investment policy fixed, firms should adjust their capital structure by smaller amounts in booms than in recessions. ${ }^{10}$ Indeed, suppose that the firm makes its initial financing decision when the economy is in an expansion and selects the coupon level $c_{H}^{0}$. Then, if the process $x$ first reaches $x_{H}^{U}$ in a boom, the firm raises debt so that its new coupon is $c_{H}^{1}=c_{H}^{0} x_{H}^{U} / x_{0}$. If the process $x$ first reaches $x_{L}^{U}$ in a recession, then the firm raises a larger debt amount so that its new coupon is $c_{H}^{0} x_{L}^{U} / x_{0}>c_{H}^{1}$. If the firm is in a recession regime when making its first financing

\footnotetext{
${ }^{10}$ Drobetz and Wanzenried (2004) use a dynamic adjustment model and panel methodology to provide a direct test of this hypothesis on a sample of 90 Swiss firms over the 1991-2001 period. Basing their tests on the dynamic panel data estimator suggested by Arrelano and Bond (1991), Drobetz and Wanzenried demonstrate that the speed of adjustment toward optimal capital structure depends on the stage of the business cycle. In particular, they demonstrate using popular business cycle variables that the speed of adjustment to the target is faster when economic prospects are better.
} 
Table 3

\begin{tabular}{llllll}
\hline & Expansion & $l$ & & & \\
\cline { 3 - 5 } & & 0.001 & 0.005 & 0.01 & 0.015 \\
\hline Dynamic & Firm value & 13.35 & 13.30 & 13.25 & 13.20 \\
model & Leverage & 25.96 & 27.70 & 28.37 & 28.51 \\
& Coupon & 0.248 & 0.262 & 0.264 & 0.265 \\
& $x_{H}^{U}$ & 1.43 & 1.87 & 2.25 & 2.59 \\
& $x_{L}^{U}$ & 1.49 & 1.96 & 2.35 & 2.70 \\
& $x_{H}^{D}$ & 0.11 & 0.12 & 0.12 & 0.17 \\
& $x_{L}^{D}$ & 0.16 & 0.17 & 0.17 & 0.17 \\
Static & Firm value & 13.07 & 13.06 & 13.04 & 13.01 \\
model & Leverage & 36.24 & 35.64 & 34.87 & 34.06 \\
& Credit spreads & 162 & 159 & 154 & 150 \\
& $x_{H}^{U}$ & $\mathrm{NA}$ & $\mathrm{NA}$ & $\mathrm{NA}$ & $\mathrm{NA}$ \\
& $x_{L}^{U}$ & $\mathrm{NA}$ & $\mathrm{NA}$ & $\mathrm{NA}$ & $\mathrm{NA}$ \\
& $x_{H}^{D}$ & 0.16 & 0.16 & 0.15 & 0.14 \\
& $x_{L}^{D}$ & 0.23 & 0.22 & 0.21 & 0.20 \\
\hline
\end{tabular}

decision, then the firm issues an initial debt contract with a smaller coupon $c_{L}^{0}$ and the above argument goes through with $c_{L}^{0}$ replacing $c_{H}^{0}$.

Finally, it should be noted that the firm's optimal leverage ratio is lower in the dynamic model than in the static model. This is due to the fact that we only consider the possibility of increasing leverage in the future (a similar point is made in Goldstein et al., 2001). When both upward and downward leverage adjustments are allowed, the leverage ratio in the dynamic model is closer to that of the static model. It should also be noted that in the dynamic model leverage increases with flotation costs while in the static model leverage decreases with flotation costs. The latter effect results from the greater costs of issuing debt that reduces optimal leverage in the static model. The former effect is due to the fact that as adjustment costs increase, the optimality (and likelihood) of future changes in leverage decreases. Thus, the optimal response for the firm is to issue an amount of debt that is closer to that of the static case.

\section{Conclusion}

When operating cash flows depend on current economic conditions, firms should adjust their policy choices to economy's business cycle phase. While this basic point has already been recognized, its implications have not been fully developed. In this paper, we present a contingent claims model of the levered firm, where operating cash flows depend on the realization of both an idiosyncratic and an aggregate shock (that reflects the state of the economy). With this model, we show that:

(1) When the aggregate shock can shift between different states, shareholders' optimal default policy is characterized by a different threshold for each state and default thresholds are countercyclical, leading to higher default rates in recessions. Moreover, 
because the states are related to one another, the value-maximizing default policy in each state reflects the possibility for the firm to default in the other states.

(2) Under this policy, default can be triggered either because the idiosyncratic shock has reached the default threshold in a given regime or because of a change in the value of the aggregate shock. As we argue in the paper, the first type of default-triggering event is unlikely to explain the clustering of exit decisions observed in many markets. By contrast, the second type provides a rationale for such phenomena.

(3) The leverage ratios that the model generates are in line with the leverage ratios observed in practice. In addition, the model predicts that market leverage should be countercyclical, consistent with the evidence reported by Korajczyk and Levy (2003).

(4) The credit spreads generated by the model are in line with those observed in practice. For any given debt level, credit spreads are higher in a recession than in a boom. The change in credit spreads following a change in the value of the aggregate shock can be substantial, reaching up to 120 basis points for financially distressed firms. In addition, the term structure of credit spreads produced by the model encompasses potentially substantial short term credit spreads.

(5) As Shleifer and Vishny (1992) conjecture, the firm's debt capacity depends on current economic conditions. Firms typically will be able to borrow more funds in a boom, even assuming a constant loss given default. If the recovery rate is procyclical, the debt capacity of the firm in a boom can be up to $40 \%$ larger than the debt capacity of that same firm in a contraction.

(6) When the firm can adjust its capital structure dynamically, both the pace and the size of the adjustments depend on current economic conditions. In particular, firms should adjust their capital structure more often and by smaller amounts in booms than in recessions.

While our model generates implications that are consistent with the available empirical evidence, it also provides a basis for future empirical work. In particular, while there is some evidence that firms financing decisions are regime dependent, there is relatively little work on the pace and size of capital structure changes across business cycle regimes. Huang and Ritter (2004) find using CRSP and Compustat data that "real GDP growth is positively associated with the likelihood of debt issuance, but is not reliably related to the likelihood of equity issuance." Drobetz and Wanzenried (2004) provide a direct test of our predictions on the pace of capital structure changes on a sample of 91 Swiss firms. Consistent with our hypothesis, they find that macroeconomic conditions affect the speed of adjustment to target leverage. In particular, the speed of adjustment is higher when the term spread is higher, i.e., when economic prospects are good. Finally, de Haas and Peeters (2004) also find that "higher GDP growth increases the adjustment speed [to target capital structure] in Estonia, Lithuania, and Bulgaria." More generally, empirical work on this topic using larger data sets is called for. We leave this issue for future research.

\section{Appendix A. Finite maturity debt value}

To solve the system of ODEs (12)-(13), define the following functions: $g \equiv d_{H}-d_{L}$ and $h \equiv \lambda_{L} d_{H}+\lambda_{H} d_{L}$. We then have the following system of equations on the 
region $x \geqslant x_{L}^{*}$ :

$$
\begin{aligned}
& \left(r+m+\lambda_{L}+\lambda_{H}\right) g(x)=\mu x g^{\prime}(x)+\frac{\sigma^{2}}{2} x^{2} g^{\prime \prime}(x) \\
& (r+m) h(x)=\mu x h^{\prime}(x)+\frac{\sigma^{2}}{2} x^{2} h^{\prime \prime}(x)+\left(\lambda_{L}+\lambda_{H}\right)(c+m p) .
\end{aligned}
$$

The general solutions to Eqs. (A.2) and (A.3) are:

$$
\begin{aligned}
& g(x)=G_{1} x^{\bar{\gamma}}+G_{2} x^{\bar{\gamma}^{\prime}} \\
& h(x)=H_{1} x^{\bar{\xi}}+H_{2} x^{\bar{\xi}^{\prime}}+\left(\lambda_{L}+\lambda_{H}\right)(c+m p) /(r+m),
\end{aligned}
$$

where $\bar{\gamma}$ and $\bar{\gamma}^{\prime}$ are the negative and positive roots of the quadratic equation

$$
r+m+\lambda_{L}+\lambda_{H}-\mu \gamma-\frac{\sigma^{2}}{2} \gamma(\gamma-1)=0,
$$

$\bar{\xi}$ and $\bar{\xi}^{\prime}$ are the negative and positive roots of the quadratic equation

$$
r+m-\mu \xi-\frac{\sigma^{2}}{2} \xi(\xi-1)=0,
$$

and $G_{1}, G_{2}, H_{1}$, and $H_{2}$ are constant parameters. The linear growth conditions

$$
\lim _{x \uparrow \infty} x^{-1} g(x)<\infty \text { and } \lim _{x \uparrow \infty} x^{-1} h(x)<\infty
$$

imply $G_{2}=H_{2}=0$. Thus, using Eqs. (A.3) and (A.4), we get

$$
d_{H}=\frac{\lambda_{H} g+h}{\lambda_{H}+\lambda_{L}} \quad \text { and } \quad d_{L}=\frac{h-\lambda_{L} g}{\lambda_{H}+\lambda_{L}} .
$$

Rearranging gives the desired expressions for debt value.

\section{Appendix B. Default policy when $m=0$}

When $m=0$, by Propositions 1 to 3 , the value of equity satisfies

$$
e_{L}(x, c)=A x^{\xi}-\lambda_{L} B x^{\gamma}+(1-\tau)\left(K_{L} x-\frac{c}{r}\right), \quad x \geqslant x_{L}^{*}
$$

and

$$
e_{H}(x, c)= \begin{cases}A x^{\xi}+\lambda_{H} B x^{\gamma}+(1-\tau)\left(K_{H} x-\frac{c}{r}\right), & x \geqslant x_{L}^{*}, \\ C x^{\beta_{1}}+D x^{\beta_{2}}+(1-\tau)\left(\frac{x y_{H}}{r-\mu+\lambda_{H}}-\frac{c}{r+\lambda_{H}}\right), & x_{H}^{*} \leqslant x \leqslant x_{L}^{*} .\end{cases}
$$


In these equations $\gamma, \xi, \beta_{1}, \beta_{2}, K_{L}$, and $K_{H}$, are defined as in Proposition 2 and $A, B, C$, and $D$ are given by

$$
\begin{aligned}
& A=\frac{(1-\tau)\left[(\gamma-1) K_{L} x_{L}^{*}-\gamma_{\frac{c}{r}}^{r}\right]}{(\xi-\gamma)\left(x_{L}^{*}\right)^{\xi}}, \\
& B=\frac{(1-\tau)\left[(\xi-1) K_{L} x_{L}^{*}-\xi_{-}^{c}\right]}{\lambda_{L}(\xi-\gamma)\left(x_{L}^{*}\right)^{\gamma}}, \\
& C=\frac{(1-\tau)\left[\left(\beta_{2}-1\right) \frac{x_{H}^{*} y_{H}}{r-\mu+\lambda_{H}}-\beta_{2} \frac{c}{r+\lambda_{H}}\right]}{\left(\beta_{1}-\beta_{2}\right)\left(x_{H}^{*}\right)^{\beta_{1}}}, \\
& D=\frac{(1-\tau)\left[\left(\beta_{1}-1\right) \frac{x_{H}^{*} y_{H}}{r-\mu+\lambda_{H}}-\beta_{1} \frac{c}{r+\lambda_{H}}\right]}{\left(\beta_{2}-\beta_{1}\right)\left(x_{H}^{*}\right)^{\beta_{2}}} .
\end{aligned}
$$

Defining $R \equiv x_{L}^{*} / x_{H}^{*}$ and plugging the above expressions for $A, B, C$, and $D$ into the continuity and smoothness conditions

$$
\begin{aligned}
& \lim _{x \downarrow x_{L}^{*}} e_{H}(x, c)=\lim _{x \uparrow x_{L}^{*}} e_{H}(x, c), \\
& \lim _{x \downarrow x_{L}^{*}} e_{H}^{\prime}(x, c)=\lim _{x \uparrow x_{L}^{*}} e_{H}^{\prime}(x, c),
\end{aligned}
$$

yields

$$
x_{H}^{*}=c \frac{\frac{1}{r} \frac{\xi}{\xi-\gamma}\left(1+\frac{\lambda_{H}}{\lambda_{L}}\right)-\frac{1}{r+\lambda_{H}}\left(1+\frac{\beta_{2} R^{\beta_{1}}-\beta_{1} R^{\beta_{2}}}{\beta_{1}-\beta_{2}}\right)}{\frac{R K_{L}}{\xi-\gamma}\left(\gamma-1+(\xi-1) \frac{\lambda_{H}}{\lambda_{L}}\right)+R K_{H}-\frac{y_{H}}{r-\mu+\lambda_{H}}\left(R+\frac{\left(\beta_{2}-1\right) R^{\beta_{1}}-\left(\beta_{1}-1\right) R^{\beta_{2}}}{\left(\beta_{1}-\beta_{2}\right)}\right)},
$$

and

$$
x_{L}^{*}=c \frac{\frac{1}{r}\left(\frac{\xi \gamma}{(\xi-\gamma)}+\frac{\lambda_{H} \xi \gamma}{\lambda_{L}(\xi-\gamma)}\right)-\frac{\beta_{1} \beta_{2} R^{\beta_{1}}-\beta_{1} \beta_{2} R^{\beta_{2}}}{\beta_{1}-\beta_{2}} \frac{1}{r+\lambda_{H}}}{R K_{L} \frac{\xi(\gamma-1)+\gamma(\xi-1) \frac{\lambda_{H}}{\lambda_{L}}}{(x i-\gamma)}+R K_{H}-\frac{y_{H}}{r-\mu+\lambda_{H}}\left(R+\frac{\beta_{1}\left(\beta_{2}-1\right) R^{\beta_{1}}-\beta_{2}\left(\beta_{1}-1\right) R^{\beta_{2}}}{\beta_{1}-\beta_{2}}\right)} .
$$

\section{Appendix C. Dynamic capital structure}

In this section we allow the firm to adjust its capital structure upwards. We assume that in the case of a restructuring, the debt is called at par: $D_{i}\left(x_{i}^{U}, c\right)=P_{i}$. Under this assumption, the value of corporate debt satisfies the set of ODEs:

- In the region $x_{H}^{U} \leqslant x \leqslant x_{L}^{U}$,

$$
r D_{L}(x)=\mu x D_{L}^{\prime}(x)+\frac{\sigma^{2}}{2} x^{2} D_{L}^{\prime \prime}(x)+\lambda_{L}\left[P_{H}-D_{L}(x)\right]+c .
$$


- In the region $x_{L}^{D} \leqslant x \leqslant x_{H}^{U}$,

$$
\begin{aligned}
& r D_{L}(x)=\mu x D_{L}^{\prime}(x)+\frac{\sigma^{2}}{2} x^{2} D_{L}^{\prime \prime}(x)+\lambda_{L}\left[D_{H}(x)-D_{L}(x)\right]+c \\
& r D_{H}(x)=\mu x D_{H}^{\prime}(x)+\frac{\sigma^{2}}{2} x^{2} D_{H}^{\prime \prime}(x)+\lambda_{H}\left[D_{L}(x)-D_{H}(x)\right]+c .
\end{aligned}
$$

- In the region $x_{H}^{D} \leqslant x \leqslant x_{L}^{D}$,

$$
r D_{H}(x)=\mu x D_{H}^{\prime}(x)+\frac{\sigma^{2}}{2} x^{2} D_{H}^{\prime \prime}(x)+\lambda_{H}\left[\alpha_{L} A_{L}(x)-D_{H}(x)\right]+c .
$$

The boundary conditions associated with this system of equations are given by

$$
\begin{aligned}
& D_{i}\left(x_{i}^{U}\right)=P_{i}, \quad i=L, H, \\
& D_{i}\left(x_{i}^{D}\right)=\alpha_{i} A_{i}\left(x_{i}^{D}\right), \quad i=L, H, \\
& \lim _{x \downarrow x_{H}^{U}} D_{L}(x)=\lim _{x \uparrow x_{H}^{U}} D_{L}(x), \\
& \lim _{x \downarrow x_{H}^{U}} D_{L}^{\prime}(x)=\lim _{x \uparrow x_{H}^{U}} D_{L}^{\prime}(x), \\
& \lim _{x \downarrow x_{L}^{D}} D_{H}(x)=\lim _{x \uparrow x_{L}^{D}} D_{H}(x), \\
& \lim _{x \downarrow x_{L}^{D}} D_{H}^{\prime}(x)=\lim _{x \uparrow x_{L}^{D}} D_{H}^{\prime}(x) .
\end{aligned}
$$

Similarly, tax benefits are akin to a security (1) that pays a constant coupon $\tau c$ as long as the firm is solvent and (2) whose value is scaled by a factor $\rho_{i}$ in regime $i$ at the time of the restructuring. Thus, tax benefits satisfy the system of ODEs:

- In the region $x_{H}^{U} \leqslant x \leqslant x_{L}^{U}$,

$$
r T B_{L}(x)=\mu x T B_{L}^{\prime}(x)+\frac{\sigma^{2}}{2} x^{2} T B_{L}^{\prime \prime}(x)+\lambda_{L}\left[\rho_{H} T B_{H}\left(x_{0}\right)-T B_{L}(x)\right]+\tau c .
$$

- In the region $x_{L}^{D} \leqslant x \leqslant x_{H}^{U}$,

$$
\begin{aligned}
& r T B_{L}(x)=\mu x T B_{L}^{\prime}(x)+\frac{\sigma^{2}}{2} x^{2} T B_{L}^{\prime \prime}(x)+\lambda_{L}\left[T B_{H}(x)-T B_{L}(x)\right]+\tau c \\
& r T B_{H}(x)=\mu x T B_{H}^{\prime}(x)+\frac{\sigma^{2}}{2} x^{2} T B_{H}^{\prime \prime}(x)+\lambda_{H}\left[T B_{L}(x)-T B_{H}(x)\right]+\tau c .
\end{aligned}
$$

- In the region $x_{H}^{D} \leqslant x \leqslant x_{L}^{D}$,

$$
r T B_{H}(x)=\mu x T B_{H}^{\prime}(x)+\frac{\sigma^{2}}{2} x^{2} T B_{H}^{\prime \prime}(x)-\lambda_{H} T B_{H}(x)+\tau c .
$$


The boundary conditions associated with this system of equations are given by

$$
\begin{aligned}
& T B_{i}\left(x_{i}^{U}\right)=\rho_{i} T B_{i}\left(x_{0}\right), i=L, H, \\
& T B_{i}\left(x_{i}^{D}\right)=0, i=L, H, \\
& \lim _{x \downarrow x_{H}^{U}} T B_{L}(x)=\lim _{x \uparrow x_{H}^{U}} T B_{L}(x), \\
& \lim _{x \downarrow x_{H}^{U}} T B_{L}^{\prime}(x)=\lim _{x \uparrow x_{H}^{U}} T B_{L}^{\prime}(x), \\
& \lim _{x \downarrow x_{L}^{D}} T B_{H}(x)=\lim _{x \uparrow x_{L}^{D}} T B_{H}(x), \\
& \lim _{x \downarrow x_{L}^{D}} T B_{H}^{\prime}(x)=\lim _{x \uparrow x_{L}^{D}} T B_{H}^{\prime}(x) .
\end{aligned}
$$

Expected bankruptcy costs are akin to a security whose only payoff is $(1-\alpha) A_{i}(x)$ at the time of default. Thus, this security satisfies the system of ODEs:

- On the region $x_{H}^{U} \leqslant x \leqslant x_{L}^{U}$,

$$
r B C_{L}(x)=\mu x B C_{L}^{\prime}(x)+\frac{\sigma^{2}}{2} x^{2} B C_{L}^{\prime \prime}(x)+\lambda_{L}\left[\rho_{H} B C_{H}\left(x_{0}\right)-B C_{L}(x)\right] .
$$

- In the region $x_{L}^{D} \leqslant x \leqslant x_{H}^{U}$,

$$
\begin{aligned}
& r B C_{L}(x)=\mu x B C_{L}^{\prime}(x)+\frac{\sigma^{2}}{2} x^{2} B C_{L}^{\prime \prime}(x)+\lambda_{L}\left[B C_{H}(x)-B C_{L}(x)\right], \\
& r B C_{H}(x)=\mu x B C_{H}^{\prime}(x)+\frac{\sigma^{2}}{2} x^{2} B C_{H}^{\prime \prime}(x)+\lambda_{H}\left[B C_{L}(x)-B C_{H}(x)\right] .
\end{aligned}
$$

- In the region $x_{H}^{D} \leqslant x \leqslant x_{L}^{D}$,

$$
r B C_{H}(x)=\mu x B C_{H}^{\prime}(x)+\frac{\sigma^{2}}{2} x^{2} B C_{H}^{\prime \prime}(x)+\lambda_{H}\left[\left(1-\alpha_{L}\right) A_{L}(x)-B C_{H}(x)\right] .
$$

The boundary conditions associated with this system of equations are given by

$$
\begin{aligned}
& B C_{i}\left(x_{i}^{U}\right)=\rho_{i} B C_{i}\left(x_{0}\right), \quad i=L, H, \\
& B C_{i}\left(x_{i}^{D}\right)=\left(1-\alpha_{i}\right) A_{i}(x), \quad i=L, H, \\
& \lim _{x \downarrow x_{H}^{U}} B C_{L}(x)=\lim _{x \uparrow x_{H}^{U}} B C_{L}(x), \\
& \lim _{x \downarrow x_{H}^{U}} B C_{L}^{\prime}(x)=\lim _{x \uparrow x_{H}^{U}} B C_{L}^{\prime}(x), \\
& \lim _{x \downarrow x_{L}^{D}} B C_{H}(x)=\lim _{x \uparrow x_{L}^{D}} B C_{H}(x), \\
& \lim _{x \downarrow x_{L}^{D}} B C_{H}^{\prime}(x)=\lim _{x \uparrow x_{L}^{D}} B C_{H}^{\prime}(x) .
\end{aligned}
$$

Finally, we assume that the firm bears proportional issuance costs $l$ when floating corporate debt. We denote the present value of these costs exclusive of the initial issuance 
costs by $I C(x, c)$. This function satisfies the system of ODEs:

- In the region $x_{H}^{U} \leqslant x \leqslant x_{L}^{U}$,

$$
r I C_{L}(x)=\mu x I C_{L}^{\prime}(x)+\frac{\sigma^{2}}{2} x^{2} I C_{L}^{\prime \prime}(x)+\lambda_{L}\left[\rho_{H}\left(I C_{H}\left(x_{0}\right)+\imath P_{H}\right)-I C(x)\right] .
$$

- In the region $x_{L}^{D} \leqslant x \leqslant x_{H}^{U}$,

$$
\begin{aligned}
& r I C_{L}(x)=\mu x I C_{L}^{\prime}(x)+\frac{\sigma^{2}}{2} x^{2} I C_{L}^{\prime \prime}(x)+\lambda_{L}\left[I C_{H}(x)-I C_{L}(x)\right], \\
& r I C_{H}(x)=\mu x I C_{H}^{\prime}(x)+\frac{\sigma^{2}}{2} x^{2} I C_{H}^{\prime \prime}(x)+\lambda_{H}\left[I C_{L}(x)-I C_{H}(x)\right] .
\end{aligned}
$$

- In the region $x_{H}^{D} \leqslant x \leqslant x_{L}^{D}$,

$$
r I C_{H}(x)=\mu x I C_{H}^{\prime}(x)+\frac{\sigma^{2}}{2} x^{2} I C_{H}^{\prime \prime}(x)-\lambda_{H} I C_{H}(x) .
$$

The boundary conditions associated with this system of equations are given by

$$
\begin{aligned}
& I C_{i}\left(x_{i}^{U}\right)=\rho_{i}\left(I C_{i}\left(x_{0}\right)+{ }_{\imath} P_{i}\right), \quad i=L, H, \\
& I C_{i}\left(x_{i}^{D}\right)=0, \quad i=L, H, \\
& \lim _{x \downarrow x_{H}^{U}} I C_{L}(x)=\lim _{x \uparrow x_{H}^{U}} I C_{L}(x), \\
& \lim _{x \downarrow x_{H}^{U}} I C_{L}^{\prime}(x)=\lim _{x \uparrow x_{H}^{U}} I C_{L}^{\prime}(x), \\
& \lim _{x \downarrow x_{L}^{D}} I C_{H}(x)=\lim _{x \uparrow x_{L}^{D}} I C_{H}(x), \\
& \lim _{x \downarrow x_{L}^{D}} I C_{H}^{\prime}(x)=\lim _{x \uparrow x_{L}^{D}} I C_{H}^{\prime}(x) .
\end{aligned}
$$

A complete solution to the above ODEs is available from the authors upon request.

\section{References}

Acharya, V., Bharath, S., Srinivasan, A., 2003. Understanding the recovery rates of defaulted securities. Working paper, London Business School.

Alderson, M., Betker, B., 1995. Liquidation costs and capital structure. Journal of Financial Economics 39, 45-69.

Allen, L., Saunders, A., 2002. A survey of the cyclical effects in credit risk measurement models. Credit Ratings. Risk Publications, London.

Altman, E., Brady, B., 2001. Explaining aggregate recovery rates on corporate bond defaults. Working paper, New York University.

Arrelano, M., Bond, S., 1991. Some tests for panel data: Monte carlo evidence and an application to employment equations. Review of Economic Studies 58, 277-297.

Barclay, M., Smith, C., 1995. The maturity structure of corporate debt. Journal of Finance 50, 609-631.

Bhanot, K., Mello, A., 2006. Should corporate debt include a rating trigger. Journal of Financial Economics 79 , 69-98. 
Black, F., Cox, J., 1976. Valuing corporate securities: some effects of bond indenture provisions. Journal of Finance 31, 351-367.

Brennan, M., Scwhartz, E., 1978. Corporate income tax, valuation, and the problem of optimal capital structure. Journal of Business 51, 103-114.

Cadenillas, A., Cvitanic, J., Zapatero, F., 2004. Leverage decision and manager compensation with choice of effort and volatility. Journal of Financial Economics 73, 71-92.

Campbell, J., 1999. Asset Prices, Consumption, and the Business Cycle. Ch. 19 in Taylor, J., Woodford, M. (Eds.), Handbook of Macroeconomics, Vol. 1. North-Holland, Amsterdam, pp. 1231-1303.

Childs, P., Mauer, D., Ott, S., 2005. Interactions of corporate investment and financing decisions: the effects of agency conflicts. Journal of Financial Economics 76, 667-690.

Cremers, M., Driessen, J., Maenhout, P., Weinbaum, D., 2005. Explaining the level of credit spreads: optionimplied jump risk premia in a firm value model. Working paper, Yale University.

David, A., 2001. Pricing the strategic value of putable securities in liquidity crises. Journal of Financial Economics 59, 63-99.

Driessen, J., 2005. Is default event risk priced in corporate bonds? Review of Financial Studies 18, 165-195.

Drobetz, W., Wanzenried, G., 2004. What determines the speed of adjustment to the target capital structure? Working paper, University of Basel.

Duffie, D., Lando, D., 2001. Term structures of credit spreads with incomplete accounting information. Econometrica 69, 633-664.

Duffie, D., Singleton, K., 2003. Credit Risk: Pricing, Measurement, and Management. Princeton University Press, Princeton, NJ.

Fama, E., 1986. Term premiums and default premiums in money markets. Journal of Financial Economics 17, $175-196$.

Fan, H., Sundaresan, S., 2000. Debt valuation, renegotiation, and optimal dividend policy. Review of Financial Studies 13, 1057-1099.

Fischer, E., Heinkel, R., Zechner, J., 1989. Dynamic capital structure choice: theory and tests. Journal of Finance 44, 19-40.

François, P., Morellec, E., 2004. Capital structure and asset prices: some effects of bankruptcy procedures. Journal of Business 77, 387-411.

Fries, S., Miller, M., Perraudin, W., 1997. Debt in industry equilibrium. Review of Financial Studies 10, 39-67.

Giesecke, K., 2002. Correlated default with incomplete information. Working paper, Humboldt University.

Gilson, S., 1997. Transactions costs and capital structure choice: evidence from financially distressed firms. Journal of Finance 52, 161-196.

Goldstein, R., Ju, N., Leland, H., 2001. An ebit-based model of dynamic capital structure. Journal of Business 74, $483-512$.

Guo, X., Miao, J., Morellec, E., 2005. Irreversible investment with regime shifts. Journal of Economic Theory $122,37-59$.

de Haas, R., Peeters, M., 2004. The dynamic adjustment towards target capital structures of firms in transition economies. Working paper, European Bank for Reconstruction and Development.

Hackbarth, D., 2004. Determinants of corporate borrowing: a behavioral perspective. Working paper, Indiana University.

Hamilton, D., Cantor, G., Ou, S. 2003. Default and Recovery Rates of Bond Issuers: 2001. Moody's Investor Service.

Hege, U., Mella-Barral, P., 2005. Repeated dilution of diffusely held debt. Journal of Business 78, 737-786.

Hennessy, C., 2004. Tobin's Q, debt overhang, and investment. Journal of Finance 59, 1717-1742.

Huang, J., Huang, M., 2002. How much of the corporate-treasury yield spread is due to credit risk? A new calibration approach. Working paper, Stanford University.

Huang, R., Ritter, J., 2004. Testing the market timing theory of capital structure. Working paper, University of Florida.

Karatzas, I., Shreve, S., 1991. Brownian Motion and Stochastic Calculus. Springer, New York.

Korajczyk, R., Levy, A., 2003. Capital structure choice: macroeconomic conditions and financial constraints. Journal of Financial Economics 68, 75-109.

Lambrecht, B., 2001. The impact of debt financing on entry and exit in a duopoly. Review of Financial Studies 14, $765-804$.

Leland, H., 1994. Corporate debt value bond covenants and optimal capital structure. Journal of Finance 49, $1213-1252$. 
Leland, H., 1998. Agency costs, risk management, and capital structure. Journal of Finance 53, 1213-1243.

Mello, A., Parsons, J., 1992. Measuring the agency cost of debt. Journal of Finance 47, 1887-1904.

Merton, 1974. On the pricing of corporate debt: the risk structure of interest rates. Journal of Finance 29, 449-470.

Miao, J., 2005. Optimal capital structure and industry dynamics. Journal of Finance 60, 2621-2659.

Modigliani, F., Miller, M., 1958. The cost of capital, corporation finance, and the theory of investment. American Economic Review 48, 261-297.

Morellec, E., 2004. Can managerial discretion explain observed leverage ratios? Review of Financial Studies 17, 257-294.

Morellec, E., 2001. Asset liquidity, capital structure and secured debt. Journal of Financial Economics 61, 173-206.

Shleifer, A., Vishny, R., 1992. Liquidation values and debt capacity: a market equilibrium approach. Journal of Finance 47, 1343-1366.

Smith, C., Warner, J., 1979. On financial contracting: an analysis of bond covenants. Journal of Financial Economics 7, 117-161.

Stohs, M., Mauer, D., 1996. The determinants of corporate debt maturity structure. Journal of Business 69, 279-312.

Zhou, C., 2001. The term structure of credit spreads with jump risk. Journal of Banking and Finance 25, 2015-2040. 